\title{
An in-depth tour into sentential complementation in Italian Sign Language
}

\author{
Carlo Geraci and Valentina Aristodemo
}

\begin{abstract}
The aim of this chapter is to explore the various strategies of sentential complementation in Italian Sign Language (LIS). Differently from what has previously been reported in the literature, namely that sentential-like complements are not allowed in center-embedded position, we describe four constructions that instantiate center-embedding of sentential-like complements in LIS. We extend the survey by including in the picture typically infinitival complements like control and raising constructions. We also investigate wh-extraction out of sentential complements and show that sentential-like complements behave as islands for wh-movement, and that d-linked wh-phrases can by-pass the islandhood status of these complements. The analysis we provide is based both on the morphosyntactic properties of LIS and on processing factors. Specifically, we show that the more processing limitations are reduced by exploiting specific grammatical resources, the more complex syntactic structures are allowed.
\end{abstract}

\section{Introduction}

Sentential complementation represents an interesting domain of investigation in that it is the first level of sentential dependency that can be established at the clausal level. The syntax of sentential complements in Italian Sign Language (LIS) is particularly interesting because of the potential interactions among language-specific structural configurations, long distance dependencies, general processing requirements, and modality specific properties of sign languages. Indeed, LIS is a head-final language and therefore complementation is expected to generate (at least one level of) center-embedding, as it happens in head-final spoken languages, like Japanese and Turkish. However, LIS also exhibits overt rightward wh-movement (Cecchetto, 
Geraci \& Zucchi 2009), a property shared with many other sign languages (see Cecchetto 2012). These first two aspects are quite challenging since both of them are problematic configurations in terms of processing. On the one hand, the processing difficulties of nested structures like center-embedding are known since the early works in the generative literature (Chomsky \& Miller 1963; Miller \& Chomsky 1963), and have been extensively studied in the relevant psycholinguistic literature (see Gibson (1998) and Babyonyshev \& Gibson (1999), among others). On the other hand, while some theoretical frameworks like the one introduced by Kayne (1994) overtly denies the existence of rightward movements, more recent researches reject this assumption (especially in the minimalist tradition) and exploit the differences (as already emerged in the early literature, e.g. Ross 1967) between left and rightward movement in syntax. Specifically, Ackema \& Neeleman (2002) argue that limitations to rightward movement in human languages are to be attributed to processing difficulties connected with short-term memory resource limitations and efforts in maintaining the gap-filler dependency across several syntactic domains. Interestingly, like in other sign languages (see Geraci, Cecchetto \& Papagno (2010) for a recent review), LIS signs have been proven to induce a quick overload in the short-term memory system, and therefore the combination of center-embedding and rightward movement should be more problematic in this language than in others (Geraci, Cecchetto \& Zucchi 2008). However, LIS also shows the typical properties of sign languages like role shift (Zucchi 2004), and a rich spatial morphology, whose investigation has only partially started (Geraci 2014). The challenge of this paper is to address the issue of whether syntactic complexity and the constraints connected to it could be alleviated by exploiting special grammatical resources that could generate processing facilitations.

In a preliminary study on sentential complements in LIS, Geraci, Cecchetto \& Zucchi (2008) showed that despite the fact that LIS can be considered a well-behaved head-final language, sentential-like complements are not allowed in center-embedded position. ${ }^{1}$ Displacement of the sentential complement either to sentence-initial or sentence-final position are the strategies adopted by LIS signers to realize sentential complementation. The only exceptions are control constructions. In fact, control constructions are allowed to sit in the center-embedded position in LIS. Also the interaction between wh-movement and sentential complementation has been partially investigated in that study, showing that wh-movement is only possible from control complements.

Recent work on Catalan Sign Language (LSC) shows that sentential center-embedding is possible under role shift (Quer 2012), an option never 
considered for LIS. This fact opens the more general question of whether there are other morphosyntactic strategies that can be employed by sign languages in order to allow for center-embedding. In this paper, we try to offer a detailed overview of these strategies for LIS and we will show that in addition to role shift, other three environments allow for sentential centerembedding in LIS. Two of them involve spatial agreement, while the third one involves the use of null pronouns (control constructions are one instantiation of this more general strategy).

In order to probe the syntactic structure of center-embedded constructions in LIS, we also investigate wh-extraction out of sentential complements both in their canonical and displaced position. The picture that will emerge is that, differently from control constructions, long distance rightward extraction of simple wh-phrases is generally not allowed out of sentential-like complements (roughly sentences with an overt embedded subject), while d-linked wh-phrases are allowed to move almost in all syntactic environments.

Although the data we provide show that the claim made in Geraci, Cecchetto \& Zucchi (2008) was too strong (as indirectly suggested by LSC data in Quer (2012)), the final picture is even more attractive in that syntactic constraints can be overruled once precise morphosyntactic and pragmatic strategies are adopted. The account that we offer for the facts of LIS appeals to both linguistic and processing factors. In a nutshell, working memory limitations run against sentential center-embedding (even at the most basic level) and against long-distance rightward movements. The syntax of LIS is such that both configurations are likely to occur and co-occur given its headfinal status and consistent rightward wh-movement. In order to cope with the general processing difficulties and the specific short-term memory limitations, the grammar of LIS displays the several strategies that are described in the paper.

Finally, given the mixed nature of our account, one caveat must be provided that concerns the acceptability status of the constructions presented in the paper. The new data presented in this paper reflect the intuitions of one Deaf informant, native signer of LIS. First, we replicated with him all the data previously reported in the literature in order to prove his consistency, and then we addressed the in-depth investigation of the new constructions. ${ }^{2}$ All data have been filmed and annotated with ELAN (Crasborn \& Sloetjes 2010).

The rest of the paper is organized as follows: Section 2 introduces background information about LIS. Section 3 presents the main data about sentential complementation, while data on wh-questions in sentential complements are discussed in Section 4. Section 5 provides a formal account to the data, while Section 6 concludes the paper. 


\section{General background on LIS}

This section describes the basic syntactic properties of the variety of LIS investigated in this paper. The reader is provided with the relevant information needed to better understand the facts about sentential complements and our account for them (see Cecchetto et al. (2006) and Cecchetto et al. (2009) for a more detailed description of LIS).

\subsection{Simple sentences}

LIS is a Subject Object Verb (SOV) language, as shown in (1a). ${ }^{3}$ Other word orders are also possible, provided that the adequate non-manual marking is present. Both OSV and SVO word order are possible with adequate spreading of the non-manual marker (brow raise $=$ 'br'). Following Cecchetto et al. (2006), we interpret this as a topic marker and thus assume that the object in the OSV sequence in (1b) is in topic position; while a constituent containing the subject and the verb is topicalized in (1c). ${ }^{4}$

(1) a. GIANNI COFFEE ORDER

'Gianni ordered a coffee.'
b. COFFEE GIANNI ORDER
'Gianni ordered a coffee.'
br
c. GIANNI ORDER COFFEE
'Gianni ordered a coffee.'

Lexical elements plausibly sitting in the functional projections of the clausal domain appear in post-verbal position. For instance, modals, the aspectual marker DONE and the negative markers all appear post-verbally, as shown in (2). Interestingly, when this happens post-verbal object configurations are harder to obtain (as also shown by the preliminary results of the corpus study in Branchini \& Geraci (2011)).

(2) a. GIANNI COFFEE ORDER CAN

'Gianni can order a coffee.'

b. GIANNI COFFEE ORDER DONE

'Gianni has ordered a coffee.' 


\section{c. GIANNI COFFEE ORDER NOT \\ 'Gianni didn't order a coffee.'}

When both negation and modal verbs appear in the same sentence, the order is rigidly MODAL $>$ NEGATION, as shown by the contrast in (3) (see also Homer \& Geraci (2013) for an analysis of the interactions between modals and negation).

\section{(3) a. GIANNI COFFEE ORDER CAN NOT 'Gianni cannot order a coffee.' \\ b. *GIANNI COFFEE ORDER NOT CAN}

Although no systematic investigation has been done in this domain, the verb system of LIS is similar to the one described for other sign languages (see Volterra (ed.) (1987) for a preliminary description). Specifically, LIS exhibits the macro-typological distinction between agreeing verbs, plain verbs and spatial verbs (Padden 1988). The first two are of main interest for the rest of the paper. In a nutshell, overt agreement is normally marked by modifying the verb trajectory (and orientation) such that the initial and final point of the articulation of the verb (or other predicates) shares the same location of the subject and the (indirect) object. To exemplify, consider the sentence in (4), where the agreeing predicate DONATE is used. The starting point of the sign DONATE is the same as that of the subject GIANNI, while the end point corresponds to the location where the indirect object MARIA is signed (see Geraci \& Quer (2014) for a recent discussion of agreement in sign languages). In the glosses, we indicate agreement via subscripts (the arrow indicates the transition from subject to object loci).

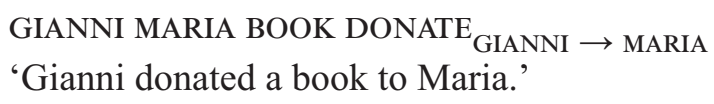

In contrast, plain verbs, which normally involve contact with some body location and do not have a path trajectory, do not modify their articulation. This is shown by the case of KNOW, which is articulated close to the forehead. In the example in (5), the articulation of the sign KNOW does not show displacement towards the positions in the signing space associated with the subject or the object (and therefore no subscripts are used).

\section{(5) GIANNI MARIA KNOW \\ 'Gianni knows Maria.'}


However, LIS offers another way to make the connection between the subject and the object visible, namely via non-manual markers. ${ }^{5}$ Specifically, rather than adjusting the verb trajectory to subject and object locations, the body of the signer slightly bends towards the position associated with the subject while the front of the torso is oriented toward the object. This strategy can be used with bodyanchored verbs, which cannot mark agreement by manipulating the trajectory of the verb due to phonological constraints. ${ }^{6}$ We indicate this type of non-manual agreement by a line above the glosses for the signs it co-occurs with. In the case of (6), the non-manual marker body lean ('bl') only co-occurs with the verb. ${ }^{7}$

$\frac{b l}{\text { (6) GIANNI MARIA KNOW }}$
'Gianni knows Maria.'

\subsection{Wh-extraction in simple sentences}

An interesting property that LIS shares with many other sign languages is the position of wh-signs in constituent questions (see Cecchetto (2012) for a review). Cecchetto et al. (2009) report that wh-signs are naturally found in the right periphery of the sentence, as illustrated by the examples in (7). ${ }^{8}$

a. GIANNI BUY WHAT

'What did Gianni buy?'

b. HOUSE BUY WHO

'Who bought a house?'

That wh-phrases occupy a position at the extreme right periphery of the clause is evidenced by the example in (8), where it is shown that the wh-phrase occurs after the modal and the negative sign.

(8) GIANNI ORDER CAN NEG WHAT

'What can't Gianni order?'

D-linked wh-phrases may either stay in situ or split moving the wh-sign and leaving the restriction in situ, as shown in (9).

(9) a. PIERO BOOK WHICH BUY

b. PIERO BOOK BUY WHICH

'Which book did Piero buy?' 
In a recent corpus study, Geraci et al. (2015) also reported cases of clauseinitial wh-phrases; our informant, however, does not accept this option. Finally, Branchini et al. (2013) reported cases of doubling of the wh-phrase in sentenceinitial and sentence-final position. This marked option, which is analyzed as the equivalent of a cleft construction, is also accepted by our informant.

\subsection{The structure of LIS}

Taking into consideration all the facts in the previous section, LIS can be considered a head-final language. The verb follows the object and the functional heads that host the aspectual marker (DONE), modals and negation all follow the main verb. As for the clause-final position of wh-signs in LIS, we assume that LIS instantiates genuine rightward movement to a right-branching SpecCP position, as extensively argued for by Cecchetto et al. (2009); topicalized phrases sit in a dedicated phrase in the CP area (Geraci, Cecchetto \& Zucchi 2008). The basic structure we assume for LIS is given in Figure 1.

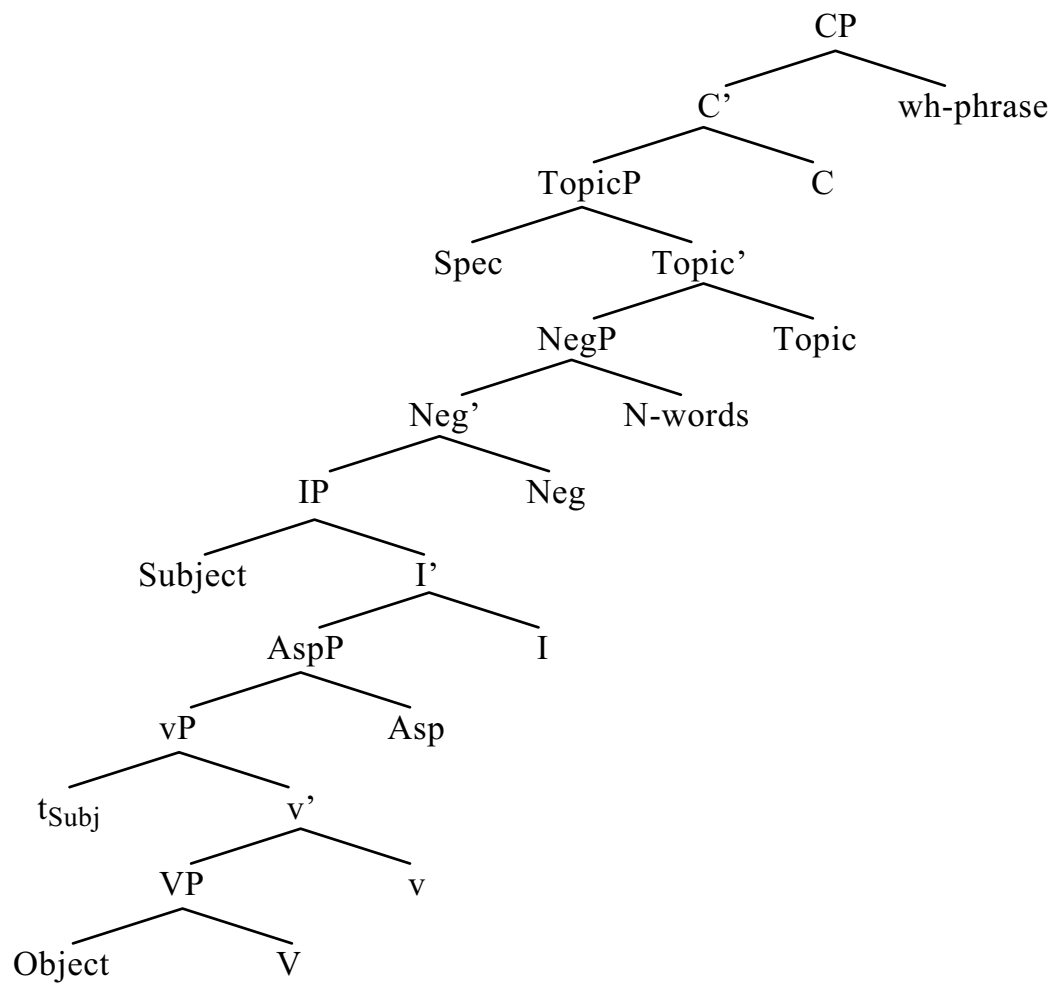

Figure 1. The basic structure of LIS. 


\section{Sentential complements in LIS}

This section summarizes and extends previous work by Geraci, Cecchetto \& Zucchi (2008) on sentential complements by discussing potential cases of raising and tough-movement constructions. New data on center-embedding are also introduced in this section. A crucial distinction that will be made in this section is the one between sentential-like and infinitival-like complements. Following Noonan (2007:59), we define sentential-like complements as a type of sentential complement with the same syntactic form as a main clause but for the presence of a complementizer. Specifically, a sententiallike complement retains the syntactic relation to its subject and its other arguments as if it occurred in a matrix clause. In the case of sign languages, where overt complementizers are normally absent, the effects of subordination connected with the $\mathrm{CP}$ are normally made visible by non-manual markers spreading over the entire subordinate CP. Thus, in our case, a sentential-like complement is a type of complement that would look like a main clause, except for the non-manual marker. In the case of LIS, what is particularly relevant is the presence of an overt subject which is not dependent on the subject of the matrix clause. This aspect makes sentential-like complements crucially different from infinitival-like complements like control constructions, where the embedded subject depends on some matrix argument, and raising predicates, where the subject of the matrix and the embedded predicate is shared via A-movement. Notice further that LIS, like many other SLs, has no overt tense morphology marked on the verb stem. Hence, the distinction between a control or raising construction and a sentential-like complement with a null subject relies on the fact that only in the former, the subject of the subordinate clause must be dependent on that of the matrix one.

Section 3.1 briefly presents the distribution of sentential-like complements following Geraci, Cecchetto \& Zucchi (2008). Section 3.2 discusses control and raising constructions, while Section 3.3 is devoted to the issue of center-embedding. The analysis for the facts introduced in this section will be presented in Section 5, following the presentation of data on wh-extraction in Section 4. It will be based on the combination of general processing requirements and structural aspects of LIS. However, without anticipating too much, we will also briefly highlight the potential processing constraints and the relevant structural configurations that by-pass them while describing the data, so that the reader is better guided towards the remainder of the paper. 


\subsection{The distribution of sentential-like complements in LIS}

The position of sentential-like complements is more restricted than the one of nominal complements in LIS. Indeed, DP complements are found at least under three configurations: SOV, SVO, and OSV. Geraci, Cecchetto \& Zucchi (2008) report that sentential-like complements are found in two positions only: they either appear before the matrix subject or after the matrix verb. Crucially, the center-embedded position, which is the canonical object position, is not available, as shown by the contrast in (10). However, as we will show in Section 3.3, center-embedding becomes possible under specific conditions.

(10) a. [PIERO BIKE FALL] GIANNI TELL
b. $\frac{\text { br }}{\text { GIANNI TELL }}$ [PIERO BIKE FALL $]^{9}$
'Gianni said that Piero fell off the bike.'
c. *GIANNI [PIERO BIKE FALL] TELL

Sentential-like complements at the beginning of the clause are optionally followed by a resumptive pronoun glossed as PRO $_{\text {RESUMPTIVE }}$. The resumptive pronoun is found either in canonical object position (11a), before the matrix subject (11b), or after the matrix verb (11c).

(11) a. $\frac{\text { br }}{\text { [PIERO BIKE FALL] GIANNI PRO }}$ RESUMPTIVE $_{\text {TELL }}$

b. $\frac{\text { br }}{\text { [PIERO BIKE FALL }] \text { PRO }}$ RESUMPTIVE $_{\text {GIANNI TELL }}$

c. $\frac{\text { br }}{\text { [PIERO BIKE FALL] GIANNI TELL PRO }}$ RESUMPTIVE 'Gianni said that Piero fell off the bike.'

Another strategy of complementation, discussed in Geraci, Cecchetto \& Zucchi (2008), is the wh-cleft construction. An example is given in (12).

GIANNI TELL WHAT PIERO CAR STEAL

'What Gianni said is that Piero stole a car.' 
Finally, some signers also allow partial repetition of the matrix subject-verb complex, as in (13), where the indexical sign IX-3 is co-referent with GIANNI.

\section{(13) GIANNI SAY [PIERO CONTRACT SIGN] IX-3 ${ }_{\text {GIANNI }}$ SAY 'Gianni said that Piero signed the contract.'}

While the wh-cleft construction is available with all types of verbs, the distribution of sentential complements in clause-initial or clause-final position is lexically constrained. For instance, when the verb THINK is used as a matrix predicate, the sentential complement may only appear after the matrix verb, as shown in (14). ${ }^{10}$ This piece of evidence is important because we will systematically capitalize on this contrast in order to probe for more complex configurations in the following sections.
a. GIANNI THINK [PIERO CONTRACT SIGN]
'Gianni thinks that Piero signed the contract.'
b. *[PIERO CONTRACT SIGN] GIANNI THINK

Unfortunately, there is no clear way to establish what the criteria are that allow or block one strategy. We summarize the pattern we identified according to a broad semantic typology:

The order in which the sentential complement precedes the main verb in a topic position is widely attested across the classes of complement-taking predicates including: utterance predicates, propositional attitude predicates (except THINK), commentative predicates.

The order in which the sentential complement is found after the main verb is available with most propositional attitude predicates, but not with TELL and negative desiderative predicates.

Repetition of the main subject and verb is available for the utterance predicate TELL and propositional attitude predicates, but not for other utterance predicates, like SAY and WARN.

The wh-cleft strategy is available for all predicates we tested.

\subsection{Control and raising constructions in LIS}

Along with sentential-like complements, the typology of sentential complementation of LIS also allows for infinitival-like sentences. Geraci, Cecchetto \& Zucchi (2008) discuss the case of control structures, that is, cases in which 
the subject of an infinitival clause must be anaphorically dependent on a specific argument of the matrix clause, be it the subject or the object. The two options are illustrated by the English examples in (15).

(15) a. John began to cry.

b. John forced Mary to eat pizza.

Once we look at these constructions in LIS, it turns out that this type of sentential complement may sit in the canonical object position between the main subject and the main verb, as shown in (16), where the subject of the complement clause is co-referent with the matrix subject. ${ }^{11}$

a. MASON [GARAGE BUILD] BEGIN DONE

'The mason began to build the garage.'

b. GIANNI [CONTRACT SIGN] FORGET

'Gianni forgot to sign the contract.'

c. GIANNI [COW MILK] TRY

'Gianni tried to milk the cow.'

Interestingly, the canonical object position is also available when the controller is an argument different from the main subject, as in the case of object control predicates like FORCE in (17).

COOK MARIA [MEAT EAT] FORCE

'The cook forced Maria to eat meat.'

However, center-embedding is not the only option for control constructions. Displacement to the left or to the right of the matrix clause is still possible. In particular, the complement can be found in the left periphery of the sentence with eyebrow raise, as in (18a), or it can be found in clause-final position in the wh-cleft construction, as in (18b). The example in (18c) involves a clause-final complement without the wh-cleft construction. ${ }^{12}$
br
a. [CONTRACT SIGN] GIANNI FORGET
b. GIANNI FORGET WHAT CONTRACT SIGN
'Gianni forgot to sign the contract.' 


\section{c. YESTERDAY GIANNI SURE [TOMORROW LEAVE] 'Yesterday Gianni was sure to leave tomorrow.'}

As for sentential complementation, another interesting case are raising constructions. Geraci (2014) discusses the examples in (19)-(21). Based on the distribution of the arguments in the signing space, he claims that (19a) involves raising of the subject from the embedded to the matrix clause. ${ }^{13}$ The same spatial distribution is found in (19b), although with a slightly different sequential order, as the complement of SEEM is center-embedded. In these examples, the sign GIANNI is articulated in the ipsilateral ('ipsi') area of the signing space, as indicated by subscripts, and it is analyzed as the raised subject of SEEM. As for the sentence in (20), the sign GIANNI is articulated in the contralateral ('contra') area of the signing space, and it is analyzed as the subject of the embedded verb WARN. The entire construction is then analyzed as a case of impersonal use of SEEM with an expletive pronoun as subject of the matrix clause, as is also evident from the English translations.
a. GIANNI IPSI $_{\text {SEEM [MARIA WARN] }}$
b. GIANNI ${ }_{\text {IPSI }}$ [MARIA WARN] $\frac{\mathrm{br}}{\text { SEEM }}$
'Gianni seems to warn Maria.'

br
head turn
[GIANNI ${ }_{\text {CONTRA MARIA WARN] SEEM }}$
'It seems that Gianni is warning Maria.'

Working on the same hypothesis of spatial distribution of verb arguments (see endnote 13), Geraci (2014) also analyzes the example in (21) as an impersonal construction, rather than a case of tough-movement (i.e. objectto-subject raising).

(21) [GIANNI CONTRA $_{\text {SATISFACTION GIVE] DIFFICULT }}$ 'It is difficult to satisfy Gianni.'

In addition to the spatial distribution discussed in Geraci (2014), a few other aspects of the syntax of the examples in (19)-(21) are interesting once compared with control constructions. The first aspect is the pattern of brow 
raise. As part of its lexical-phonology, SEEM co-occurs with raised eyebrows. This makes topicalization particularly hard to detect, especially when the subject, which is often topicalized, is adjacent to the verb. Indeed, anticipatory brow raise on the subject may be confused with topicalization. However, the fact that brow raise does not co-occur with the sign GIANNI in example in (21) can be taken as evidence that GIANNI is not in topic position. This is also confirmed by the contrast in (22). In (22a), the time adverb YESTERDAY intervenes between the subject GIANNI and the verb SEEM indicating, in addition to brow raise, that the subject has been topicalized to the left of the adverb. In (22b), the time adverb YESTERDAY does not intervene and GIANNI is not apparently marked by any special non-manual component, showing that no topicalization has occurred. ${ }^{14}$
a. $\frac{b r}{\text { GIANNI }_{\text {IPSI }}} \frac{\text { br }}{\text { YESTERDAY SEEM SICK }}$
$\frac{\mathrm{br}}{\text { b. YESTERDAY GIANNI IPSI }}$ SEEM SICK
'Yesterday Gianni seemed sick.'

The second piece of evidence supporting the raising vs. impersonal analysis of the examples in (19) and (20) is the compatibility of two time adverbs in the same utterance. In fact, only in the impersonal construction YESTERDAY and TODAY may co-occur, as shown by the contrast in (23) and (24). On the other hand, control constructions allow, although marginally, the two time adverbs, as in (25).

a. *YESTERDAY EVENING GIANNI ${ }_{\text {IPSI }}$ SEEM LEAVE TODAY

b. *YeSTERDAY EVENING GIANNI ${ }_{\text {IPSI }}$ SEEM TODAY LEAVE

c. *YESTERDAY EVENING GIANNI ${ }_{\text {IPSI }}$ TODAY LEAVE SEEM

d. * Yesterday EVENING GIANNI ${ }_{\text {IPSI }}$ LEAVE TODAY SEEM Intended: 'Yesterday evening, it seemed that Gianni was to leave today.'

(24)
br
YESTERDAY EVENING [GIANNI CONTRA $_{\text {LEAVE TODAY] SEEM }}$
'Yesterday evening it seemed that Gianni was to leave today.' 
??YESTERDAY EVENING GIANNI [LEAVE TODAY] SURE

'Yesterday evening Gianni was sure to leave today.'

A final aspect concerns the examples in (20) and (21), which are analyzed as impersonal constructions with a null expletive. If this analysis is correct, then both examples involve a sentential-like complement and, prima facie, they should be treated as cases of center-embedding with a null expletive pronoun serving as the matrix subject. This possibility is discussed in the next session.

\subsection{The issue of center-embedding in LIS}

The fact that sentential complements are hard to find in center-embedded position in LIS is quite remarkable considering that this is the unmarked position for nominal complements. Anticipating the discussion to be developed in Section 5, Geraci, Cecchetto \& Zucchi (2008) attribute this fact to the general difficulty of having center-embedded configurations even in spoken languages. While most of the spoken languages tolerate at least one level of center-embedding, LIS does not tolerate any. Part of the explanation they offered relies on the connection between the experimental finding of short term memory limitation for LIS (Geraci et al. 2008) and the working memory overload that results from the processing of center-embedded configurations. The grammar of LIS adopts the different strategies illustrated in Section 3.1 in order to cope with this limitation. Center-embedding becomes possible when the working memory load is reduced and, the authors argue, this is the case in control constructions (and raising constructions, as we showed in Section 3.2). In this section, we further explore this possibility by investigating other potential cases of center-embedding and how these are handled by the grammar of LIS. The picture that emerges is more intricate than the one previously described in the literature, according to which sentential-like complements are not allowed in center-embedded position, while infinitival-like complements are. In fact, it will turn out that center-embedding is allowed even with sentential-like complements in LIS, but only under strict conditions which involve one of the following morphosyntactic options: role shift, a special use of the signing space, and null subject pronouns.

Before turning to these cases, we would like to explore in more detail what counts as heavy in terms of working memory overload in LIS. The first aspect we would like to investigate is whether the quantity of lexical material might force displacement of a control complement. The first observation that 
we can make is that nominal complements do not need to be displaced even when they are relatively complex, as in (26). ${ }^{15}$

(26) GIANNI [SNOW-WHITE STORY IX-3 POSSESSIVE $]$ TELL 'Gianni told Snow white's story.'

Similarly, displacement of a control complement is not mandatory, even when it is lexically heavy, that is, the sentential complement can occur in the canonical object position. The example in (27) illustrates the case of an object control construction with a lexically heavy object. Specifically, the complement of the (center)-embedded verb EAT is composed of three lexical items (GRILLED, CHICKEN, and MEET).

COOK MARIA [GRILLED CHICKEN MEET EAT] FORCE

'The cook forced Maria to eat grilled chicken meet.'

Crucially, a further level of sentential center-embedding is not tolerated, as shown by the unacceptable (28a). One of the strategies available to convey the intended meaning is exemplified in (28b), where the second level of sentential embedding (MILK BUY) is actually in topic position as signaled by the relevant non-manual marker. Unsurprisingly, the strategy to avoid complex structures like double center-embedding is one of those available with sentential-like complements, namely topicalization.

a. *GIANNI [MARIA [MILK BUY] WARN] FORGET

$\frac{\mathrm{br}}{\text { b. }}$
'GILK BUY] GIANNI [MARIA WARN] FORGET
'Gianni forgot to remind Maria to buy milk.'

Interestingly though, the second level of center-embedding is allowed if the sentence is under role shift, as shown in (29), where role shift is (mainly) realized as body shift toward the position in space where GIANNI is signed.

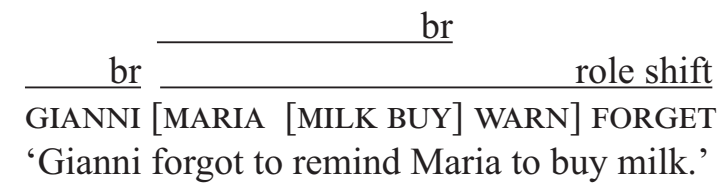

The effect of role shift on center-embedding was first noticed in Catalan Sign Language by Quer (2012), where it was shown that center-embedding with 
sentential-like complements is possible under role shift. The same pattern is found in LIS, as shown in (30). Interestingly, the sentence is ambiguous between a reading where role shift induces indexical shifting (the first person pronoun is interpreted as 'the person who is warning') and a non-shifted reading in which the pronoun refers to the signer.

$$
\frac{\text { br }}{\text { VALENTINA IX-3 }} \frac{\text { role shift }}{\text { VALENTINA }}
$$

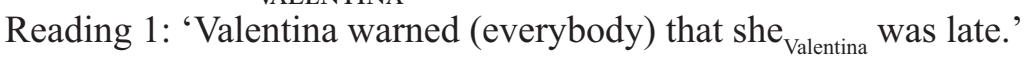

Reading 2: 'Valentina warned (everybody) that $\mathrm{I}_{\text {signer }}$ was late.'

The ameliorating effect of role shift on center-embedding is not limited to sentential complements with pronominal subjects, but it is also found with full DPs as subject, as shown in (31). ${ }^{16}$
role shift
VALENTINA IX-3 VALENTINA [PIETRO BEANS EAT] WARN
'Valentina warned (you/someone) that Pietro eats beans.'

In combination with a control complement, role shift may generate a construction with two levels of center-embedding. Interestingly, under role shift, it is also possible to find a second level of center-embedding with a sentential-like complement, as shown in (32). ${ }^{17}$
role shift
GIANNI [MARIA MILK BUY WARN MARIA $\rightarrow$ GIANNI $_{\text {[ FORGET }}$
'Gianni forgot that Maria warned (him) that she had bought the milk.'

Although the sequence of signs in (32) is identical to (29), the main difference is that in (32) the verb of the first embedded complement (WARN) agrees with the overt subject (MARIA) and with the body (i.e. the roleshifted object GIANNI), and therefore should be counted as a sentential-like complement. The subject of WARN then controls the subject of the further embedded verb BUY.

In addition to role shift, sentential-like complements are allowed in center-embedded position in LIS under a special use of the signing space. In this option, the position in the signing space where the matrix subject is located serves as the place of articulation of the matrix verb. An example is given in (33). The citation form of the LIS verb WARN is articulated at the level of the mouth (like SAY) with an outward path movement executed at the elbow joint. It normally shows agreement with a silent indirect object. ${ }^{18}$ However, in the example in (33), the verb detaches from the body and takes 
the location associated with its subject as its place of articulation (this is indicated by the subscript). This operation suffices to turn an otherwise unacceptable sentence into a grammatical LIS sentence. ${ }^{19}$

$$
\begin{aligned}
& \text { VALENTINA IX-3 } \text { VALENTINA }_{\text {[IX-1 ARRIVE LATE] WARN }} \text { VALENTINA } \\
& \text { 'Valentina warned that I (the signer) was late.' } \\
& \text { \#'Valentina warned that I (Valentina) was late.' }
\end{aligned}
$$

However, differently from role shift, the sentence is not ambiguous between a shifted and non-shifted interpretation of the indexicals, as shown by the unavailable shifted interpretation of the first person pronoun. Without spatial localization of the verb, the sentence is unacceptable, as already noted by Geraci, Cecchetto \& Zucchi (2008), and this is evident from the contrast between (33) and (34a). Notice further that this morphological operation is not required when one of the other strategies to avoid center-embedding are used (topicalization, rightward displacement, or wh-cleft), as in (34b-d), or when a control construction is used, as in (34e).

$$
\begin{aligned}
& \text { a. *VALENTINA IX-3 } 3_{\text {VALENTINA }} \text { [IX-1 }{ }_{\text {SIGNER }} \text { ARRIVE LATE] WARN } \\
& \text { b. VALENTINA IX-3 } 3_{\text {VALENTINA }} \text { WARN [IX-1 }{ }_{\text {SIGNER }}^{\text {ARRIVE LATE }]} \\
& \text { c. [IX-1 } \left.{ }_{\text {SIGNER }} \text { ARRIVE LATE }\right] \text { VALENTINA IX-3 } 3_{\text {VALENTINA }} \text { WARN } \\
& \text { 'Valentina warned that I was late.' }
\end{aligned}
$$

d. VALENTINA IX-3 $3_{\text {VALENTINA WARN WHAT IX-1 }} 1_{\text {SIGNER }}$ ARRIVE LATE 'What Valentina warned about is that I was late.'
e. VALENTINA IX-3 $3_{\text {VALENTINA }}$ [ARRIVE LATE] WARN 'Valentina warned to be late.'

The option in (33), unnoticed in previous works, is also available with other predicates, like TELL, whose place of articulation has probably already started an independent process of detachment from the body. However, not all complement-taking predicates allow for this strategy. One of these is SAY, as shown by the unacceptability of the example in (35). ${ }^{20}$

$$
\text { *VALENTINA IX-3 } 3_{\text {VALENTINA }} \text { [IX-1 ARRIVE LATE] SAY valENTINA }
$$

Crucially though, there is another strategy, again previously unnoticed, that allows center-embedding even with this type of predicates. Rather 
than detaching the place of articulation, as in (33), or using body shift (and other non-manual markers) to introduce role shift, as in (30), a non-manual agreement strategy may be used, namely body lean. In these cases, the body bends towards the location associated with the subject, as already shown in (6) above. The same non-manual marker may optionally co-occur with the subject, as shown in (36).

(body lean)

body lean

VALENTINA (IX-3 ${ }_{\text {VALENTINA }}$ ) [IX-1 ARRIVE LATE] SAY

'Valentina said that I (the signer) was late.'

\#'Valentina said that I (Valentina) was late.'

Examples like (36) are very similar to cases of role shift if we look just at the manual material and at the macroscopic articulatory effect of posture modification (in both cases, the body of the signer "ideally" reaches the location associated with one of the arguments of the verb). However, the operation in (36) is different from role shift for at least three reasons, one phonological, one prosodic, and one semantic: (i) the non-manual component is different (body shift/turn vs. body lean); (ii) the spreading domain is different (wide spreading in role shift vs. no spreading); (iii) there is no ambiguity once looking at the indexicals, as shown by the unaccessible shifted reading in (36), which is marked with the '\#' symbol. ${ }^{21}$

The last case of center-embedding that we present here is the one involving null elements (specifically, null subjects), either in the matrix clause or in the embedded clause in constructions other than control. Two cases of null expletive subjects in the matrix clause have already been introduced in Section 3.2. These were cases of impersonal constructions, the full patter is given in (37) and (38).
a. $\frac{\text { br }}{\text { [GIANNI }_{\text {CONTRA }} \text { CONTRACT SIGN] SEEM }}$
b. [GIANNI CONTRA $_{\text {CONTRACT SIGN] SEEM }}$
'It seems that Gianni is signing the contract.'
br
a. [GIANNI ${ }_{\text {CONTRA }}$ SATISFACTION GIVE] DIFFICULT
b. [GIANNI CONTRA $_{\text {SATISFACTION GIVE] DIFFICULT }}$ 'It is difficult to satisfy Gianni.'

(38) 
The examples in (37a) and (38a) involve topicalization of the sentential complement (across the null expletive subject), and are therefore not real cases of center-embedding; rather they might display the usual strategy to avoid center-embedding already discussed in Geraci, Cecchetto \& Zucchi (2008) and reported in Section 3.1. More interesting are the examples (37b) and (38b). In these cases, topicalization should not be involved, as there is no brow raise on the sentential object, and the examples are to be considered as genuine cases of center-embedding, assuming that the null expletive subject precedes the sentential complement.

However, center-embedding is not possible when the matrix subject is an overt pronoun realized as a pointing to a previously introduced location, and it is also excluded in the case of pro-drop, as shown in (39). Crucially, the sentence with the overt pronoun becomes acceptable if detachment of the matrix verb is realized, as in (40a). However, the null pronoun strategy is not acceptable in the same environment, as is shown by the contrast between (40a) and (40b), where the overt matrix pronoun is replaced by a null pro.

a. *GIANNI ROOM ENTER. IX-3 MARIA ARRIVE LATE WARN

b. *GIANNI ROOM ENTER. pro MARIA ARRIVE LATE WARN Intended structure: $\left[_{\mathrm{CPmatrix}}\left[_{\text {IPmatrix }}\right.\right.$ IX-3 $\left[_{\mathrm{VPmatrix}}\left[_{\mathrm{CP} \text { subordinate }}\right.\right.$ MARIA ARRIVE LATE] WARN]]]

Intended meaning: 'Gianni entered the room. He warned (us) that Maria would have arrived late.'

(40) a. GIANNI ROOM ENTER. IX-3 ${ }_{\text {IPSI }}$ [MARIA ARRIVE LATE] WARN ${ }_{\text {IPSI }}$ 'Gianni entered the room. He warned (us) that Maria would have arrived late.'

b. *GIANNI ROOM ENTER. pro [MARIA ARRIVE LATE] WARN ${ }_{\text {IPSI }}$

Crucially, center-embedding is possible when the subject of the embedded clause is dropped, as in (41). In this case, the sentence is ambiguous between a control reading (or a role-shifted reading) and a reading in which a null pronominal subject refers to the signer (i.e. a null first person pronoun). This second reading is the relevant one here since it clearly involves a sentential-like complement.

\section{(41) MARIA [EARN STRONG] KNOW}

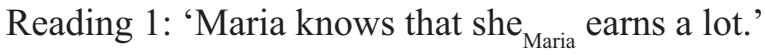

Reading 2: 'Maria knows that I (the signer) earn a lot.' 
Crucially, in the center-embedded cases involving null pronouns, the matrix predicates (SEEM, DIFFICULT, and KNOW in (37), (38), and (41)) do not employ any of the strategies presented above: there is no role shift (in the relevant reading), no phono-morphological detachment of the predicate towards a position in the signing space, and no body lean towards any location where verb arguments are positioned in the neutral space. What is interesting, however, is the presence of a null element (expletive subject or null pronoun) serving as the matrix subject or embedded subject. At the beginning of this section, we presented evidence that the amount of lexical material in the sentential complement of a control construction does not affect the availability of the center-embedded position (see the discussion around the example (27) above). What we observe in these last cases is that the presence/absence of an overt subject is relevant in determining the acceptability of a center-embedded configuration. We will come back to this aspect in Section 5.1.

\section{Wh-questions and sentential complements}

In this section, we explore the interaction between the various strategies of complementation and wh-movement. We start by presenting the case of wh-movement from the subject position of the matrix clause (Section 4.1), and then focus on extraction out of sentential complements (Section 4.2). Data on wh-movement of matrix subjects will show the relevance of processing factors in determining the preference for constructions where the gap-filler linear distance is short. As for wh-extraction from sentential complements, we will show that in addition to extraction out of control constructions, wh-movement occurs out of right-adjoined complements but not from topicalized complements. However, this option is only allowed under d-linked wh-questions. Some cases of apparent wh-movement will be also discussed. In order to establish whether the data under discussion are genuine cases of extraction or two separate clauses, we used the insertion of the conjunction BUT as a diagnostics. If the conjunction BUT can be inserted between the rest of the sentence and the final wh-sign, then we take the utterance as made up by two independent clauses, an assertion followed by an elliptical clause made up by the adversative sign BUT and the wh-sign. If BUT cannot be inserted, we consider the utterance as monoclausal instantiating genuine wh-movement. 


\subsection{Questioning the subject of a matrix clause}

Overt wh-movement from the subject of the matrix clause to the sentencefinal position is freely allowed in the case of preverbal sentential complements, as shown in (42).

$$
\begin{aligned}
& \frac{\mathrm{br}}{[\text { PIERO BIKE FELL }]} \mathrm{t}_{\text {WHO }} \text { SAY WHO } \\
& \text { 'Who said that Piero fell off the bike?' }
\end{aligned}
$$

This configuration is also possible for complement-taking predicates only allowing post-verbal sentential objects in declarative sentences. This is the case of the verb THINK. The contrast in (43) shows that the sentential complement of THINK is only allowed in post-verbal position, as already shown in (14). However, the pattern in (44) indicates a preference for wh-movement from the matrix subject when the complement is in topic position. The contrast is even more impressive once we consider the version with the resumptive pronoun in $(44 b)$.

\section{a. GIANNI THINK [PIERO BIKE FELL]}

'Gianni thinks that Piero fell off the bike.'

b. *[PIERO BIKE FELL] GIANNI THINK
a. ?? $\frac{\text { br }}{\text { [PIERO BIKE FELL] }} \mathrm{t}_{\text {WHO }}$ THINK WHO

br

b. [PIERO BIKE FELL] $\mathrm{t}_{\mathrm{WHO}}$ THINK PE WHO

c. $\quad$ * ${ }^{\mathrm{WHO}}$ THINK [PIERO BIKE FELL] WHO

'Who thinks that Piero fell off the bike?'

The data in this section shows a clear tendency to avoid wh-movement crossing sentential complements in LIS. This pattern nicely fits with Akema \& Neeleman's (2002) account for the fact that rightward movements need to be "short". In this case, the grammar of LIS offers a way to reduce the linear filler-gap distance by removing the intervening sentential complement. Notice further that $(44 \mathrm{c})$ realizes at the $\mathrm{CP}$ level a center-embedded configuration, which is avoided in (44a) and (44b). The respective structures are sketched in (45). 
(45)

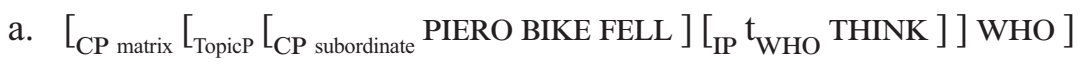

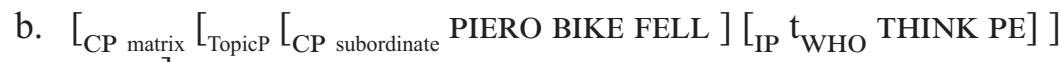 WHO ]
c. $\left[_{\mathrm{CP} \text { matrix }}\left[_{\mathrm{IP}} \mathrm{t}_{\mathrm{WHO}}\right.\right.$ THINK $\left[_{\mathrm{CP} \text { subordinate }}\right.$ PIERO BIKE FELL $\left.]\right]$ WHO $]$

\subsection{Questioning the sentential complement}

Geraci, Cecchetto \& Zucchi (2008) reported that wh-phrases cannot be extracted out of a displaced sentential object, and that extraction is possible from the center-embedded position in control constructions. We replicated the same pattern, as shown in (46) and (47).
a. *[PIERO $\mathrm{t}_{\mathrm{WHICH}}$ SIGN] GIANNI SAY WHICH ${ }^{22}$
b. *GIANNI SAY [PIERO $t_{\text {WhiCH }}$ SIGN] WHICH Intended: 'What did Gianni say Piero signed?'
(47) a. GIANNI $t_{\text {WHICH }}$ SIGN FORGET WHICH
b. $\left[_{\mathrm{CP}}\left[_{\mathrm{IP}}\right.\right.$ GIANNI $\left[_{\mathrm{CP}}\right.$ PRO $\mathrm{t}_{\mathrm{WHICH}}$ SIGN $]$ FORGET $]$ WHICH $]$ 'What did Gianni forget to sign?'

However, the pattern of wh-questions targeting elements inside sentential complements is more intricate especially in light of the new findings discussed in Section 3. We present here new data on control structures and raising constructions, then we will turn to movement out of sentential-like complements. We will see that in d-linked contexts, wh-extraction out of sentential-like complements is possible only if the complement is not topicalized.

The special status of control constructions is also visible when the control complement is displaced either to sentence-initial or sentence-final position. Indeed wh-extraction is possible when the complement is topicalized, as in (48) (as usual, topicalization is marked by brow raise).

(48) a. BUY GIANNI FORGET WHICH

b. $\left[_{\mathrm{CP} \text { matrix }}\left[_{\text {Topic }}\left[\left[_{\mathrm{CP} \text { subordinate }} \mathrm{t}_{\mathrm{WHICH}} \mathrm{BUY}\right]\left[_{\text {IP }}\right.\right.\right.\right.$ GIANNI FORGET $\left.] \mathrm{WHICH}\right]$ 'What has Gianni forgotten to buy?' 
The pattern of wh-extraction in the case of clause-final complement is less neat. While extraction is perfectly acceptable in the case of WANT, as in (49a), it is only possible in d-linked contexts with other predicates, as in (49b). As we will see, the need for d-linking is a more general property of wh-extraction out of sentential-like complements.

\section{a. GIANNI WANT $\left[\mathrm{t}_{\text {WHICH }}\right.$ SELL $]$ WHICH \\ 'What does Gianni want to sell?'}

b. GIANNI IMAGINE [ $\mathrm{t}_{\text {[WHICH IX-LOC] }}$ SELL] [WHICH IX-LOC] 'Which of these does Gianni imagine to sell?'

In the case of topicalization induced by the second level of embedding, wh-extraction is not possible. A bi-clausal strategy is used instead, as shown by the contrast in (50). That the example in (50b) instantiates a bi-clausal utterance is shown by the possibility of BUT insertion.

a. $*\left[\mathrm{t}_{\mathrm{WHICH}}\right.$ BUY $]$ GIANNI MARIA WARN FORGET WHICH

b. $\frac{\text { br }}{\text { [BUY IX-3] GIANNI MARIA WARN FORGET (BUT) WHICH }}$ 'Gianni forgot to warn Maria to buy that. But what is it?'

Wh-extraction is also possible in raising constructions but not in their impersonal counterpart, as shown by the contrast in (51):

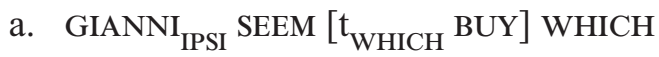
'What did Gianni seem to buy?'

b. $*_{\text {GIANNI }}$ CONTRA $\left[\mathrm{t}_{\text {WHICH }}\right.$ BUY $]$ SEEM WHICH

Intended meaning: 'What does it seem that Gianni bought?'

Remember from Section 3 that the position of the subject GIANNI in the ipsilateral part of the signing space is used as a diagnostic for the raising status of the seem-construction. In contrast, articulation of the subject in the contralateral part of the signing space would yield an impersonal construction.

Moving to sentential-like complements, we found that while wh-extraction out of topicalized complements is not allowed (confirming the previous finding in Geraci, Cecchetto \& Zucchi (2008)), short wh-movement is possible. The result is an indirect question, as shown in (52). The position of 
the wh-subject in (52b) clearly indicates that internal movement to the right periphery of the sentential complement has occurred.
a. [PIERO $t_{\text {WHICH }}$ SIGN WHICH] GIANNI SAY
'Gianni said what Piero signed.'
b. $\left[\mathrm{t}_{\text {WHO }}\right.$ CONTRACT SIGN WHO] GIANNI SAY 'Gianni said who signed the contract.'

When the sentential complement follows the matrix verb, short wh-movement is also possible. The optional presence of role shift makes the construction ambiguous between a direct and an indirect discourse reading, as shown in $(53) .^{23}$

a. GIANNI SAY [PIERO $t_{\text {WHICH }}$ VOTE WHICH]

Reading 1: 'Gianni said what Piero voted for.'

Reading 2: "Gianni said: "What did Piero vote for?",

b. GIANNI SAY [ $\mathrm{t}_{\mathrm{WHO}}$ CONTRACT SIGN WHO]

Reading 1: 'Gianni said who signed.'

Reading 2: 'Gianni said: "Who signed?",

The fact that no answer is required in the examples in (53) confirms that they do not involve direct questions. The indirect discourse reading, connected with the indirect question interpretation, is more readily accessible in the following piece of discourse:

\section{(54) SURE GIANNI SAY [PIERO $t_{\text {WHICH }}$ VOTE WHICH] BUT YOU FORGET 'For sure Gianni said you what Piero voted for, but you forgot!'}

Turning to matrix questions, differently from what we found in topicalized sentential-like complements, we have been able to elicit wh-movement from sentential complements that are in clause-final position. However, this is only possible in a d-linked context, as shown by the contrast in (55). As in the example (49b), d-linking is exemplified by the presence of a complex wh-phrase consisting of a wh-sign plus a locative pointing sign towards the location where the group of men was located in previous discourse. Interestingly, this type of d-linked wh-phrases exploits the signing space to make acceptable an otherwise impossible clause. We will come back to this aspect in Section 5. 
a. MARIA THINK [ $\left.\mathrm{t}_{\text {[WHO IX-LOC] }} \mathrm{RICH}\right]$ [WHO IX-LOC]

'Who of them does Maria think is rich?'

b. *MARIA THINK $\mathrm{t}_{\mathrm{WHO}}$ RICH WHO ${ }^{24}$

That (55) involves wh-movement out of the embedded clause is confirmed by the fact that insertion of the conjunction BUT before the wh-phrase is not possible, as shown in (56).

* MARIA thinK [ $\mathrm{t}_{\text {[WHO IX-LOC] }}$ RICH] BUT [WHO IX-LOC]

One interesting piece of data concerning the underlying structure of sentences like (55) is given in (57).

\footnotetext{
a. $\quad t_{\text {[WHO IX-LOC] }}$ EARN STRONG $]$ MARIA THINK [WHO IX-LOC] 'Who of them does Maria think earns a lot of money?'
}

b. *EARN STRONG MARIA THINK BUT WHO IX-LOC

c. *PIERO EARN STRONG MARIA THINK

Three things are relevant here: (i) no brow raise is observed on the preposed sentential complement, showing that no topicalization is involved (57a); (ii) BUT insertion is not possible (57b), which is evidence of the mono-clausal status of the entire utterance; (iii) the verb THINK does not allow preverbal sentential-like complements (cf. (57c) and the similar examples already discussed in (14) and (43)). In Section 5, we will argue that example (57a) is the overt manifestation of an intermediate stage in the derivation of sentences like (55).

Turning now to sentential-like complements in center-embedded position not introduced by role shift, we found that wh-extraction is possible, but crucially only in d-linked contexts. The examples in (58) and (59) illustrate the case of a center-embedded complement with pronominal and full DP subjects, respectively.
a. MARIA [IX-1 $\mathrm{t}_{\text {[IX-LOC WHICH] }}$ EAT] WARN [IX-LOC WHICH] 'Which of these has Maria warned (you/someone) that I ate?'
b. *MARIA IX-1 EAT WARN WHICH Intended: 'What has Maria warned (you/someone) that I ate?' 
c. *MARIA IX-1 EAT WARN BUT IX-LOC WHICH

Intended: 'Maria warned that I ate (something). But which of these (things)?'

d. MARIA [IX-1 IX-LOC ${ }_{\text {ARC }}$ EAT] WARN BUT IX-LOC WHICH

'Maria warned (you/someone) that I ate one of those. But which one?'

(59) a. MARIA [PIERO t [IX-LOC WHICH] EAT] WARN IPSI $[$ IX-LOC WHICH] 'Which of these has Maria warned (you/someone) that Piero ate?'

b. *MARIA PIERO EAT WARN ${ }_{\text {IPSI }}$ WHICH Intended: 'What has Maria warned (you/someone) that Piero ate?'

c. *MARIA PIERO EAT WARN ${ }_{\text {IPSI }}$ BUT IX-LOC WHICH Intended: 'Maria warned that Piero ate (something). But which of these (things)?'

d. MARIA [PIERO IX-LOC ${ }_{\text {ARC }}$ EAT] WARN IPSI $_{\text {BUT IX-LOC WHICH }}$ 'Maria warned (you/someone) that Piero ate one of those. But which one?'

The contrast between (58a) and (58b) and between (59a) and (59b) shows the relevance of d-linking for wh-extraction. The fact that BUT insertion is not possible (cf. (58c) and (59c)) further confirms that these are genuine cases of wh-extraction. In contrast, insertion of the conjunction BUT is possible in $(58 \mathrm{~d})$ and $(59 \mathrm{~d})$, where a pronominal element is used as object of the embedded verb. ${ }^{25}$

Finally, the pattern of wh-questions in the case of center-embedded complements introduced by role shift is given in (60).

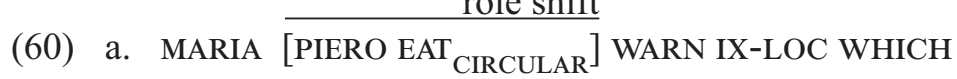

'Which of these has Maria warned (someone) that Piero ate?'

role shift

b. MARIA [PIERO EAT $\left.{ }_{\text {CIRCULAR }}\right]$ WARN BUT IX-LOC WHICH 'Maria warned (someone) that Piero ate one of those. But which one?' 
role shift

c. MARIA [PIERO IX-LOC ${ }_{\text {ARC }}$ EAT] WARN BUT IX-LOC WHICH 'Maria warned (someone) that Piero ate one of those. But which one?'

Just like with sentential complements without role shift, the bi-clausal strategy with an overt pronominal element as object of the embedded verb is available, as shown in (60c). Interestingly, both (60a) and (60b) are also acceptable, although there is no overt pronoun serving as the object of EAT. However, in both cases, the verb instantiates a repeated wide circular movement (as indicated by the subscript) starting in the neutral space and passing the mouth at the mid-circle point. This movement is clearly different from the repeated short path movement close to the mouth found in the other examples involving EAT. We assume that this manipulation of movement and place of articulation is the morphological manifestation of object agreement under role shift and that this suffices to license a null pronominal element as the object of EAT. This sharply contrasts with the unacceptable examples in (58c) and (59c), where no agreement is available (see also endnote 25). Under these reasonable assumptions, (60b) and (possibly) (60a) are equivalent to (60c) in involving a bi-clausal strategy.

Once we look at role-shifted complements in clause-final position, a similar pattern is observed, as is shown in (61).
role shift
a. GIANNI THINK IX-3 ARRIVE LATE WHO
'Who does Gianni think arrived late?'
role shift
b. GIANNI THINK [IX-3 ARRIVE LATE] BUT WHO
'Gianni thinks that one of them will arrive late. But who?'

Thus, we tentatively conclude that extraction out of role-shifted complements is not possible in LIS.

\section{The analysis of sentential complements}

The data presented in Sections 3 and 4 provide a much more complex picture than the one described in the preliminary work by Geraci, Cecchetto \& Zucchi (2008). The basic pattern discussed in that paper has been replicated 
without problems in the present study. However, more and new data, especially concerning the availability of center-embedding and the extraction of wh-phrases in d-linked contexts, cast some doubts on certain aspects of their formal analysis. Nonetheless, we maintain that two conspiring factors processing and grammar - are needed to account for all patterns of sentential complementation in LIS. Indeed our new data reinforce our original claim. Specifically, two main facts have to be accounted for: the first one is the distribution of sentential-like complements in center-embedded position; the second one is the pattern of wh-questions. We address each of these issues in turn.

\subsection{The analysis of center-embedding in LIS}

Concerning the distribution of sentential-like complements, in addition to the previous strategies which always involved some sort of syntactic mechanism of displacement to avoid the center-embedded configuration, we have now identified at least four options that license sentential-like complements in the center-embedded position. These are: (i) role shift, (ii) spatial agreement involving the place of articulation of the verb, (iii) spatial agreement involving a specific non-manual marker (body lean), and (iv) the presence of null subjects either in the form of a null expletive in the matrix clause, or as null pronouns in the subject position of the embedded complement (in addition to control constructions). The analysis we propose for these constructions will also allow us to offer a more precise account for topicalized complements and clause-final complements not involving wh-clefting, which will be fully developed in sections 5.2 and 5.3.

The basic tenet of our account is based on two facts. The first one is that center-embedding produces a generalized working memory overload (see, among others, Gibson 1998). This overload is at least partially connected to the interference of potential subjects. Indeed, Arnon et al. (2007) notice that the acceptability of multiple center-embedding in English significantly improves once the embedded subjects are replaced by pronouns, as shown by the contrast in (62) (Arnon et al. 2007:1). A similar pattern is observed in the Italian examples in (63), where the most embedded subject is a null pronoun.

(62) a. The boy the cat the dog bit scratched started crying.

b. The correspondent everyone I met trusts is interviewing the president. 
a. Il ragazzo che il professore che la mamma odia ha biasimato è infelice.

'The boy the professor the mother hates blamed is unhappy.'

b. Il ragazzo che tutti quelli che odio hanno biasimato è infelice.

'The boy everyone I hate blamed is unhappy.'

The second fact is that a component of working memory, namely shortterm memory, is sensitive to the phonological weight of signs. Specifically, Geraci, Cecchetto \& Zucchi (2008) claim that the structure of LIS signs (and possibly those of other sign languages as well) generates a short-term memory overload more rapidly than words in spoken languages.

We claim that the combination of these two factors produces a rapid working memory overload in LIS signers. Specifically, what seems to be problematic is keeping information about the matrix subject syntactically active across the articulation of the embedded constituent. This is so, because of the potential interference of subordinate subjects, similar to what we observed in the spoken language examples presented in (62a) and (63a). In the absence of any processing facilitation, these facts impose a generalized ban on center-embedded constructions in LIS, and the center-embedded sentential-like complement is therefore displaced either to a sentence-initial topic position or to a sentence-final position.

Turning to constructions that allow for center-embedding, the rationale of our account is based on the observation that neutral facial expression and neutral body posture do not license sentential-like center-embedding in LIS, while nominal complements, control and raising constructions may appear in that position without requiring special morphology or non-manual markers. In fact, morphological information must be further specified (as in the case of overt agreement) or selectively removed (e.g. by using null pronouns) in order to allow for center-embedding in sentential-like complements. Crucially, the relevant information that is manipulated in all cases is information concerning the subject either of the matrix clause or of the embedded clause (this is also true in the case of control and raising complements).

As for role shift and the two spatial agreement constructions, a morphological solution clearly exploits spatial strategies of some sort, thus helping recovering information about the matrix subject. The matrix subject is the one undergoing role shift and it is the one attracting verb detachment and body lean. On the one hand, in the case of role shift, the body of the signer becomes the matrix subject itself and, in a certain sense, information about the matrix subject is therefore always present and immediately recoverable 
throughout the sentence. On the other hand, spatial agreement helps reactivating and recovering information about the matrix subject at the time the matrix verb is articulated.

In the case of null expletive subjects, no sign is produced at the ipsilateral side of the signing space, keeping that location syntactically active to mark the presence of the null expletive pronoun.

As for null subjects in embedded constructions, we distinguish three types of center-embedded configurations: raising subjects, control constructions, and null first person subjects. Here, too, space seems to play a crucial role. Indeed, in the first two cases, the spatial location is shared between an argument in the matrix clause and the embedded null subject. In raising constructions, there is only a single subject shared by the matrix and the embedded verb, therefore the same spatial location is also shared. In control constructions, the embedded subject must share the location with the controller in the matrix clause, otherwise control fails. ${ }^{26}$ In both cases, the potential intervention effect of the embedded subject is mitigated thanks to the dependency on an argument of the matrix clause. In the case of null first person pronouns in the embedded clause, information about the null subject is recoverable by virtue of the fact that the signer's body itself instantiates the pronoun (on the relevance of body as subject in sign languages, see Meir et al. (2007)).

We now turn to the specific analyses of each of these constructions by starting with role shift. Role shift has an impact on sign order of sentential complements in LIS, showing an active role not just in the semantic component but also in the syntactic component. ${ }^{27}$ We adopt Quer's (2005) proposal for Catalan Sign Language (developed based on Lillo-Martin's (1995) seminal work) and assume the presence of a covert point of view predicate sitting in the head of the Speech Act Phrase of the subordinate clause. Therefore, the structure of the example in (30), repeated here as (64), is the one given in Figure 2. The representation in Figure 2 is an adaptation of Quer's proposal to the head-final structure of LIS.

(64) VAlENTINA IX-3 ${ }_{\text {VALENTINA }}$ [IX-1 ${ }_{\text {valentina }}$ ARRIVE LATE] WARN 'Valentina warned (everybody) that she ${ }_{\text {(Valentina) }}$ was late.' 


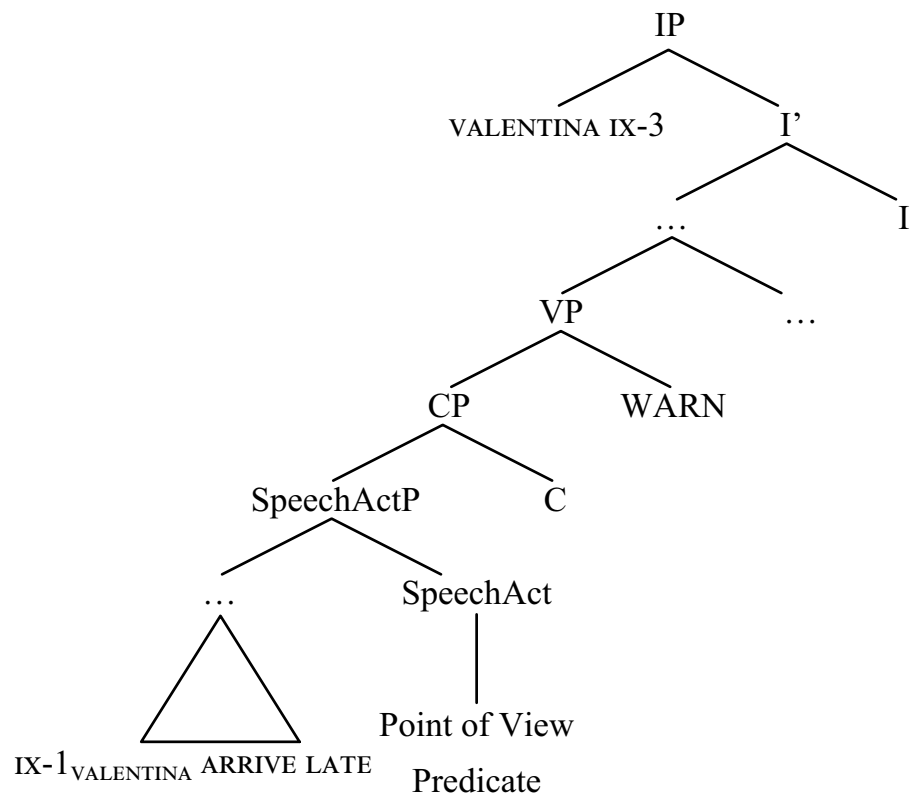

Figure 2. Structure of sentential-like center-embedded complements with role shift.

In order to manage the interaction of overt attitude predicates that lexically introduce role shift with the covert point of view predicate, Quer (2005) further assumes movement of the covert predicate to the head of the matrix verb phrase, resulting in the incorporation into the matrix attitude predicate (as also proposed in Speas (2000, 2004)). Again, we follow Quer (2005) in his assumption, and we also speculate that partial evidence supporting Quer's assumption and his analysis can be found in the derivation of clausefinal complements under role shift in LIS. The derivation of the example in (65) is given in Figure 3.

'Gianni thinks that Maria will arrive late.' 


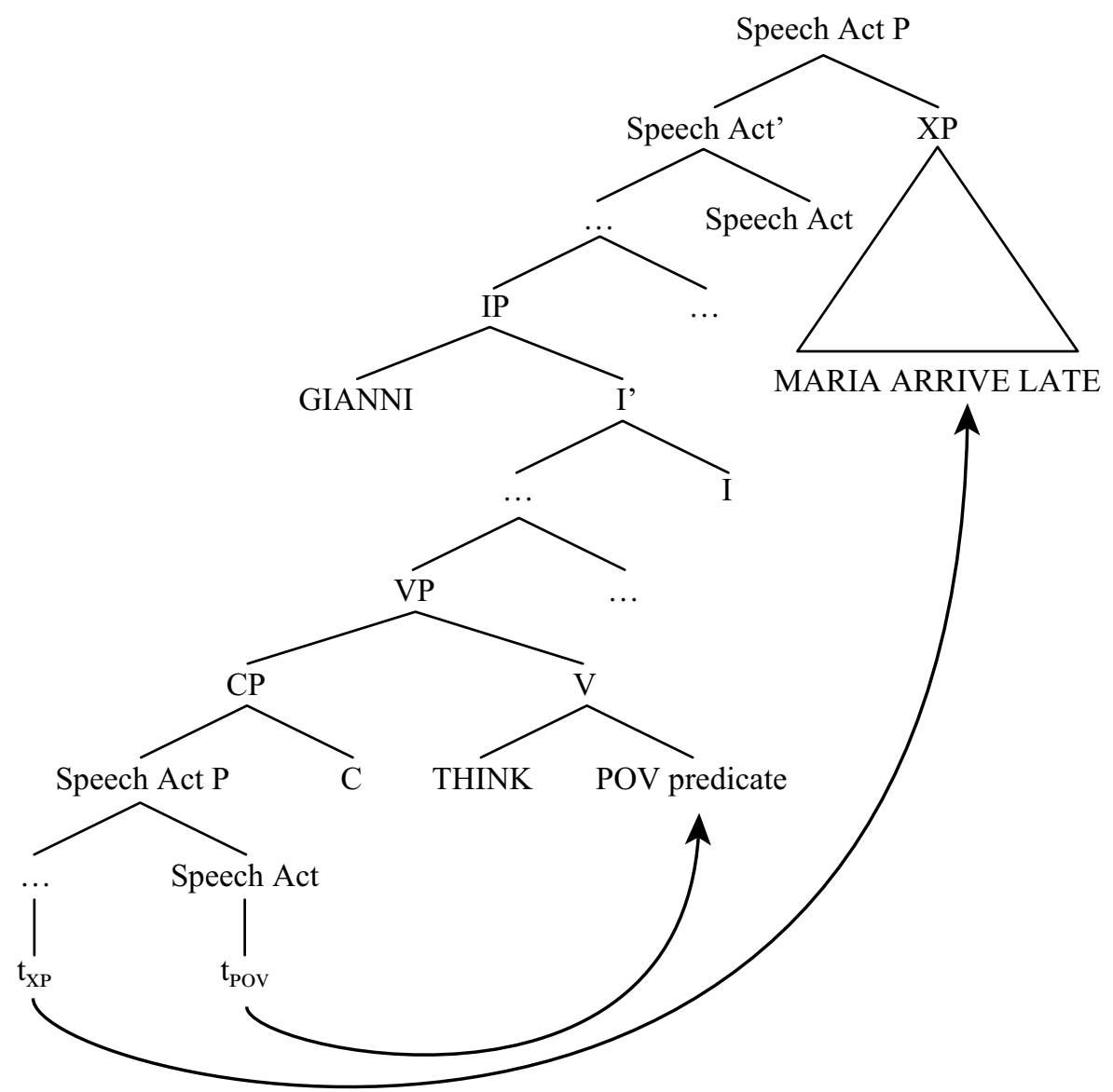

Figure 3. Role shift and clause-final complements.

The sentential complement undergoes rightward movement from the centerembedded position to the projection hosting the point of view predicate of the matrix clause, realizing a Spec-head configuration. This operation is likely to take place after the subordinate point of view predicate has been incorporated into the lexical matrix verb and has entered a probe-goal relation with the matrix Speech Act Phrase. ${ }^{28}$ The rightward movement analysis is supported by the fact that other types of movement, like wh-movement and n-word movement, are clearly rightward in LIS (see Geraci 2006; Cecchetto, Geraci \& Zucchi 2006; Geraci 2009; Geraci \& Cecchetto 2013). Interestingly, the landing sites of both these movements are likely to be criterial positions in the sense of Rizzi (2006). If the specifier of the Speech Act Phrase also counts as a criterial position, then once the sentential complement has moved 
to that position, no further movement is expected to be possible. Indeed this seems to be the case, since topicalization of sentential complements under role shift is not possible in LIS (see also endnote 23). ${ }^{29,30}$

Turning now to verb detachment and body lean, a natural analysis for these constructions is that they involve markers of agreement and that the two phenomena are instantiations of the same underlying mechanism. The appearance of one or the other depends on a phono-morphological constraint operating at the lexical level. Verbs that are not specified for the body as place of articulation (although they do not necessarily have to be agreeing verbs in the sense of Padden (1988)) or that detach from the body may relocate to the position in space where the subject is produced. If this option is not available due to phonological constraints (e.g. a [+contact] feature that cannot be deleted), then the body lean option is used. To illustrate, we provide the structure for the example in (36), repeated as (66), in Figure 4.

(body lean)

body lean

VALENTINA (IX-3 ${ }_{\text {IPSI }}$ ) IX-1 ARRIVE LATE SAY

'Valentina said that I (the signer) was late.'

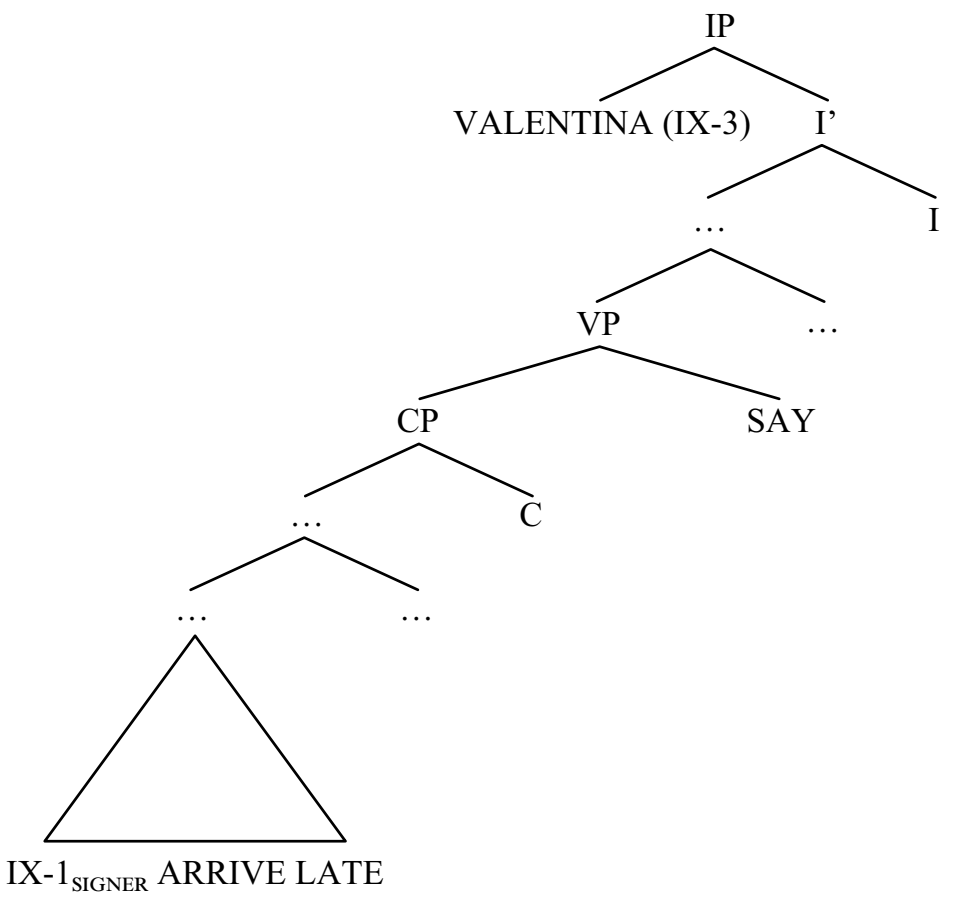

Figure 4. Structure of sentential-like center-embedded complements without role shift. 
Much like in the case of role shift (see endnote 28), we do not have clear evidence that the verb further moves to the head of an agreement phrase. Given current minimalist mechanisms, a probe-goal relation might suffice even to justify the presence of the relevant non-manual markers on the clause-final verb.

As for null expletive constructions, the syntax we adopt is quite standard. In Figure 5, we provide the structure for the example in (37b), repeated here as (67).

GIANNI $_{\text {CONTRA }}$ CONTRACT SIGN SEEM

'It seems that Gianni is signing the contract.'

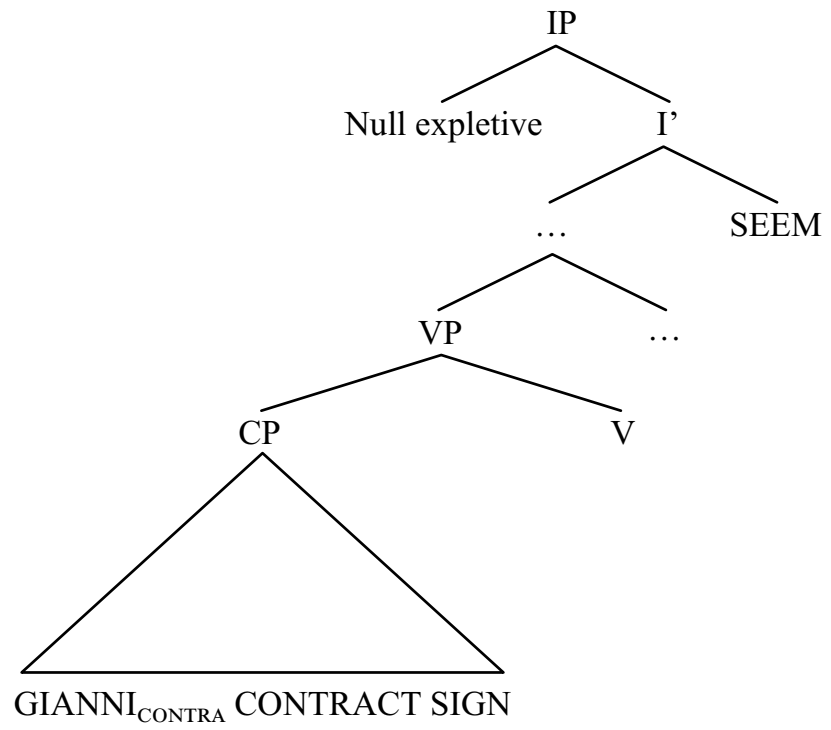

Figure 5. Structure of impersonal SEEM construction.

Before concluding this section, we would like to emphasize one important aspect of our analysis, which is the interaction between grammatical principles and processing constraints. The original speculation that centerembedding in LIS is not allowed due to processing overload caused by working memory limitations (Cecchetto et al. 2006; Geraci, Cecchetto \& Zucchi 2008) is further confirmed by our data.

As is now clear from the new facts presented in Section 3 and the discussion in this section, sentential center-embedding crucially undermines the relationship between the matrix subject and the matrix verb. This is probably due to the interference of the embedded subject. This interference can 
be avoided in three ways: (i) by displacing the sentential complement and therefore reducing the linear distance between subject and verb (as described in Geraci, Cecchetto \& Zucchi (2008)); (ii) by using spatial strategies (role shift, spatial agreement); or (iii) by using null pronouns (subject raising, control and first person pro in embedded clauses, or null expletives in matrix clauses). Crucially, the last two options allow for center-embedding.

Once these strategies are available and fruitfully applied, even a double level of embedding is tolerated as shown in (29), repeated here as (68), where role shift introduces the first-level center-embedding, and subject control introduces the second level. It seems that in this respect, the picture is not different from spoken languages, where a second level of center-embedding becomes readily available once the appropriate subjects are chosen, as has already been shown by the English and Italian examples in (62) and (63).

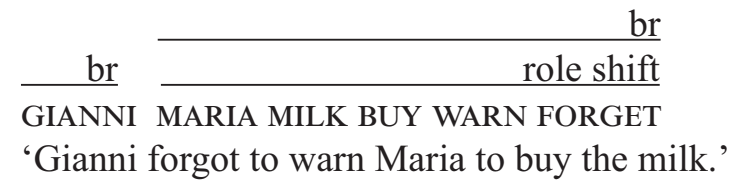

To conclude, processing facilitations introduced by spatial morphology and specific syntactic configurations may allow sentential complements to remain in the canonical object position.

\subsection{The analysis of wh-extraction in LIS}

Concerning the pattern of wh-questions, we have seen (i) that wh-movement from the matrix subject position may generate word order reorganization making the topic position available to elements that are not allowed to be topicalized in the declarative counterpart; (ii) that wh-movement out of sentential-like complements in topic position is not allowed, while wh-movement is possible out of controlled constructions that sit in topic position in the surface syntax; (iii) that movement out of a sentential-like complement in center-embedded position is possible in d-linked contexts in the absence of role shift; and (iv) that movement out of a clause-final complement is possible in d-linked contexts, again if no role shift is involved.

Before turning to wh-extraction out of sentential complements, we would like to briefly sketch an analysis of wh-movement from the matrix subject position. From a syntactic viewpoint, there is nothing particularly 
problematic in these constructions. For the sake of illustration, the representation of sentence (44a), repeated here as (69), is given in Figure 6.

(69) ?? $\overline{\text { [PIERO BIKE FELL] }} \mathrm{t}_{\mathrm{WHO}}$ THINK WHO

'Who thinks that Piero fell off the bike?'

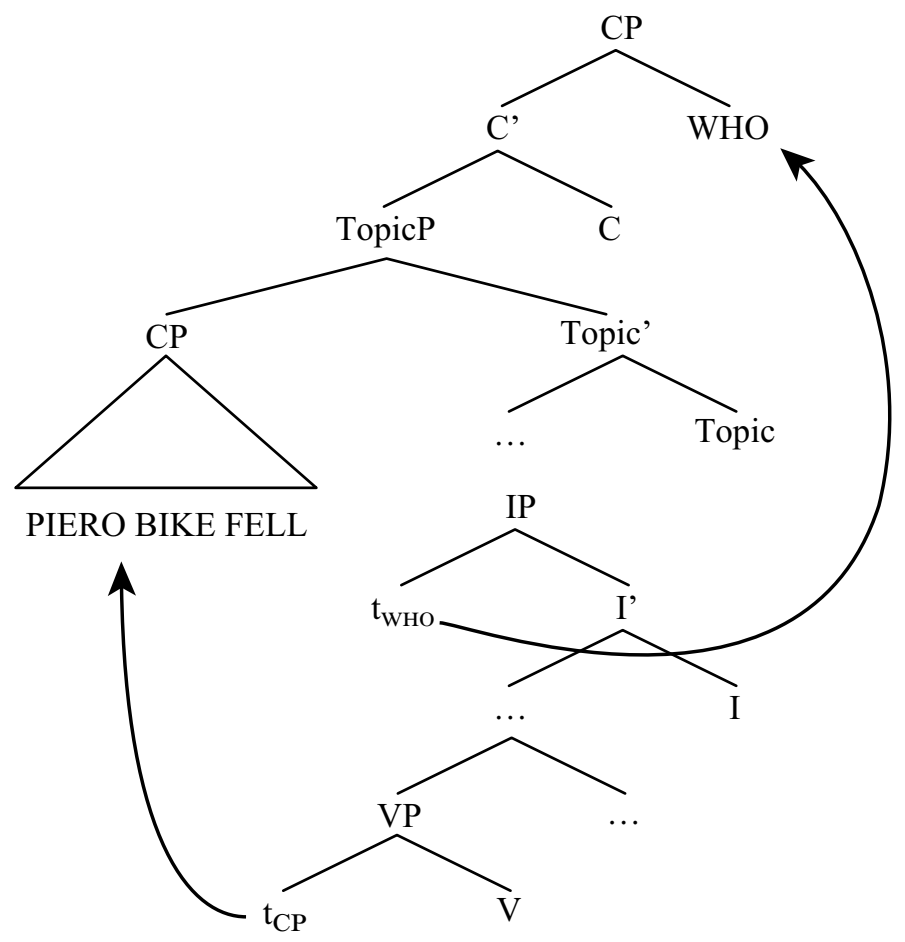

Figure 6. Wh-movement of matrix subject.

The interesting aspect of these constructions concerns the different levels of acceptability of the various options attested in LIS. Specifically, extraction is less acceptable when the sentential complement intervenes between the gap in subject position and the moved wh-phrase in SpecCP, than when the intervening complement is displaced in topic position (see examples (44) above). We interpret this difference in acceptability as a processing effect. Specifically, reducing the (linear) distance between the gap and the filler improves acceptability (on the effects of processing rightward movement in spoken languages, see Akema \& Neeleman (2002)).

Turning now to wh-extraction out of sentential complements, the overall picture that emerges is that simple wh-extraction is not possible out of 
sentential-like complements in LIS, even with verbs that are normally bridge verbs in spoken languages. ${ }^{31}$ Working on the contrast between factive and non-factive verbs in spoken languages, De Cuba (2007) proposes that a richer CP structure is present in non-factive complements. Specifically, he claims that an extra projection within the CP layer of the complement of nonfactive verbs provides the escape hatch for wh-movement. Unfortunately, we cannot rely on a fine-grained structure for CP layers in LIS; however, we can tentatively assume that either LIS sentential-like complements are missing this projection or that this position is not immediately accessible to simple wh-phrases. Under this view, sentential-like complements behave like syntactic islands, independently of their position in the surface syntax (center-embedded, topicalized, or clause-final). The only exceptions are d-linked wh-phrases. In these contexts, the islandhood of sentential-like complements is relaxed, and wh-extraction is possible except when the complement is in topic position. ${ }^{32,33}$ Remember from the previous section that this type of d-linking exploits the signing space (and a pointing sign) to locate the restriction of the complex wh-phrase. As in the case of centerembedding, we would like to suggest that the particular use of the signing space made available in d-linked contexts helps processing the gap-filler chain, making wh-movement from the sentential-like CP acceptable. The relevant pattern is given in (70) and (71). Notice that none of the examples involves role shift.

(70) a. *PIERO $t_{\text {WHICH }}$ SIGN GIANNI WARN $($ IPSI) WHICH

b. *GIANNI WARN (IPSI) PIERO $t_{\text {WHICH }}$ SIGN WHICH

(71) a. MARIA [PIERO $t_{[\text {IX-LOC WHICH] }}$ EAT] WARN ${ }_{\text {IPSI }}$ [IX-LOC WHICH]

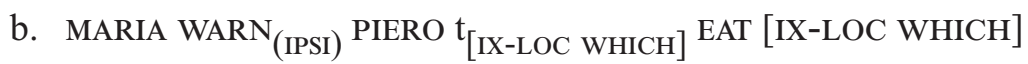
'Which of these has Maria warned (you/someone) that Piero ate?'

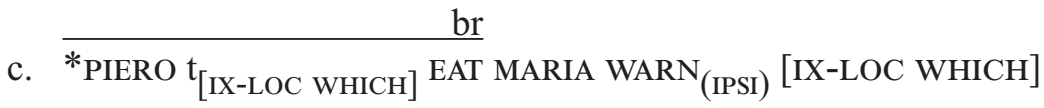

The different acceptability status of (71b) and (71c) can be taken as evidence that the two constructions are intrinsically different and that a unified account for the islandhood of the two constructions is not possible. ${ }^{34} \mathrm{On}$ the one hand, one could account for (71c) by following Geraci, Cecchetto \& Zucchi (2008) and argue that the topicalized element is base-generated in topic position. ${ }^{35}$ Hence, the islandhood introduced by the topic phrase should 
be assumed to be stronger than the one generated by center-embedded or clause-final complements. On the other hand, the patterns reported in (71) seem to suggest a unified account for (71a) and (71b). This is perfectly in line with Geraci, Cecchetto \& Zucchi (2008), who derived the clause-final position of sentential complements by scrambling the sentential object to the left of the subject, and then moving the remnant to topic position. As already mentioned in endnote 30 , the authors used examples with partial repetition like (72) as evidence for leftward scrambling. In the present paper, we have further evidence for this intermediate step, which is provided by example (57a), repeated here as (73).

GIANNI TELL PIERO BIKE FELL GIANNI TELL

'Gianni told that Piero fell off the bike.'

$$
\begin{aligned}
& \text { [ } \mathrm{t}_{\text {[WHO IX-LOC }]} \text { EARN STRONG ] MARIA THINK [WHO IX-LOC] } \\
& \text { 'Who of them does Maria think earns a lot of money?' }
\end{aligned}
$$

In (73), the sentential complement is in clause-initial position, although no brow raise co-occurs with it. This can be taken as evidence that the complement is not topicalized (and is not base-generated in topic position either). We argue that this configuration instantiates the intermediate step in the derivation of clause-final complements. Specifically, we argue that the sentential complement in (73) has scrambled to the left of the matrix subject and that remnant movement has not occurred. ${ }^{36}$ Since this configuration instantiates an intermediate derivational step between center-embedded and clause-final complements, d-linked wh-phrases are expected to be possible, as confirmed by (73). Furthermore, the fact that d-linked wh-questions are possible in this configuration provides further evidence for the stronger islandhood status of topicalized constructions. Before discussing further this aspect, let us focus on the derivation of (71a) and (71b). As for (71a), the wh-phrase cyclically moves through the embedded CP thanks to its d-linked status and reaches the matrix SpecCP. The derivation is shown in Figure 7. 


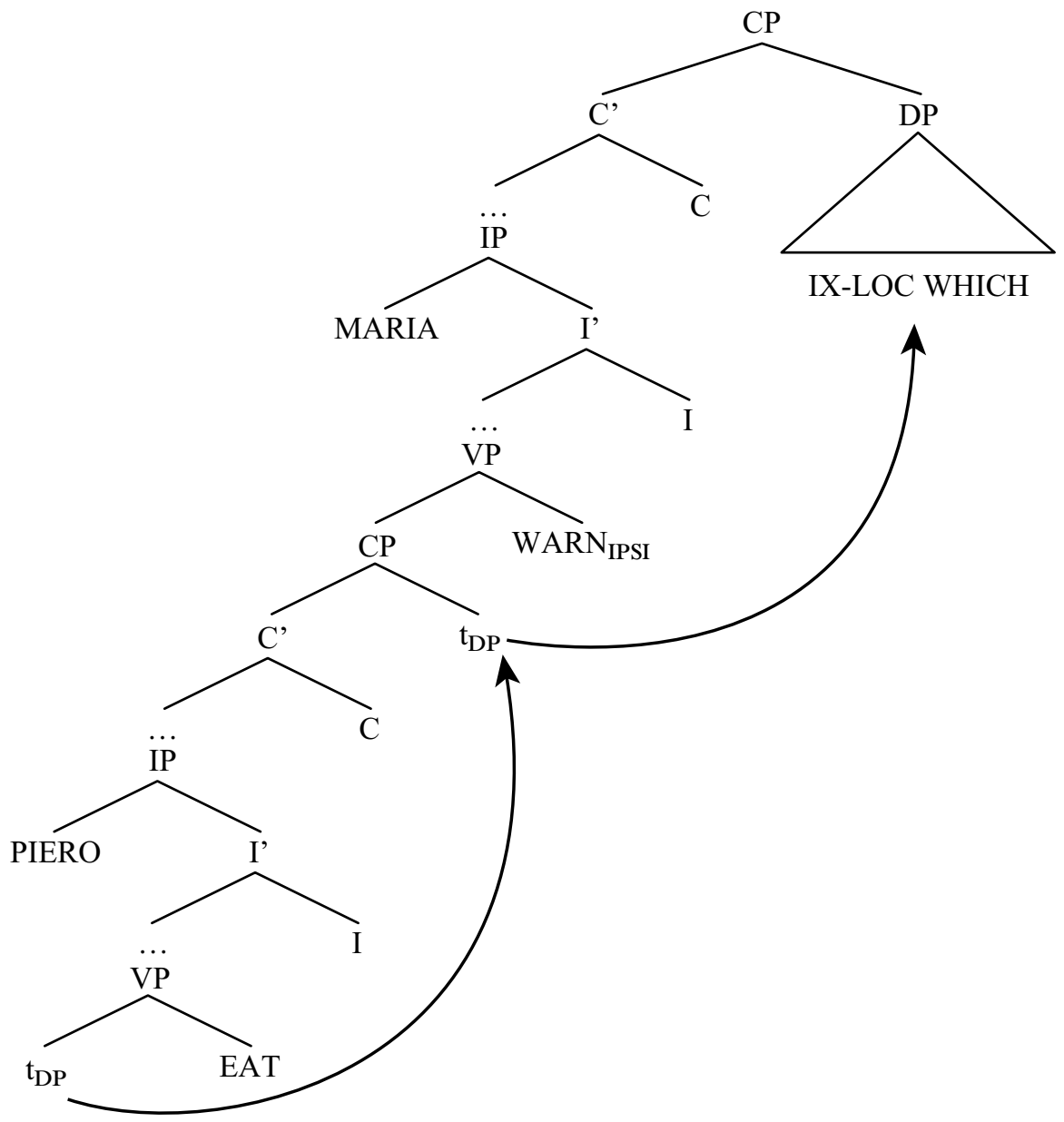

Figure 7. Extraction of d-linked wh-phrase from embedded CP.

The derivation of (71b) (and (73)) would be similar to that of (71a), with two further steps, namely scrambling and remnant movement, as shown in Figures 8 to 10. First, the complex wh-phrase is extracted from the embedded CP by rightward movement to SpecvP (Figure 8). ${ }^{37}$ Subsequently, the embedded $\mathrm{CP}$ is scrambled leftwards and the complex wh-phrase is moved further to SpecCP of the matrix CP (Figure 9). Finally, the IP is topicalized (Figure 10). 


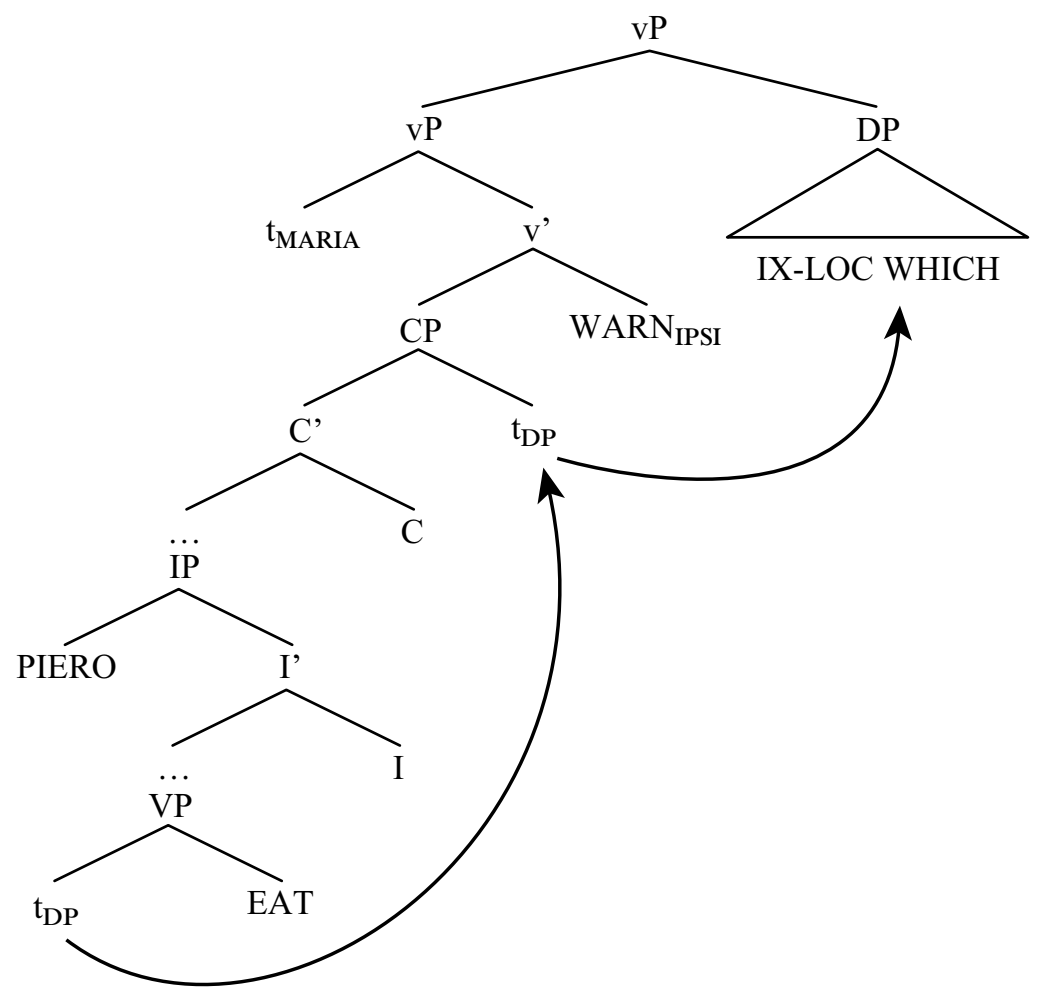

Figure 8. D-linked wh-phrase in clause-final complements: wh-extraction. 


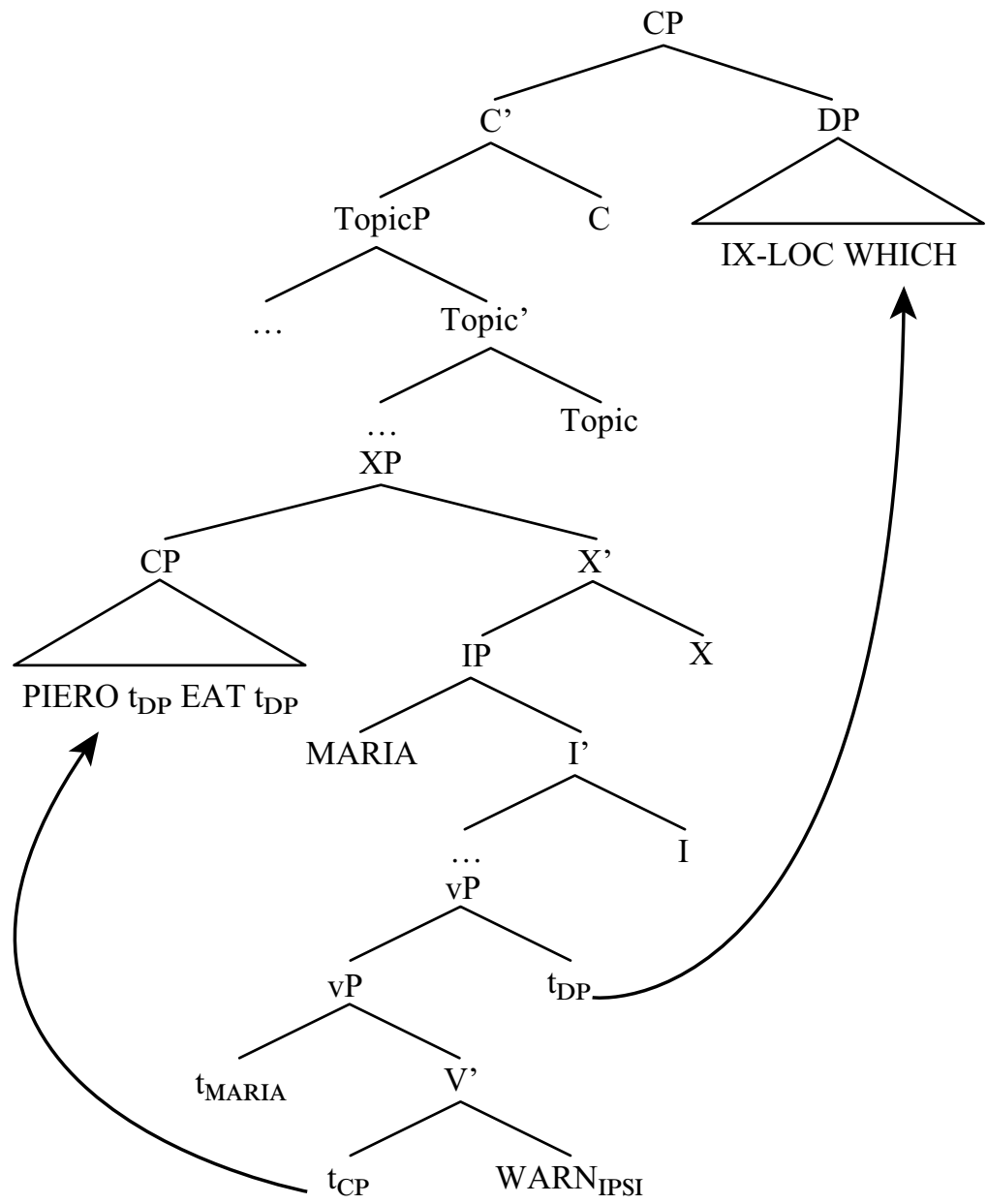

Figure 9. D-linked wh-phrase in clause-final complements: CP scrambling \& movement to SpecCP. ${ }^{38}$ 


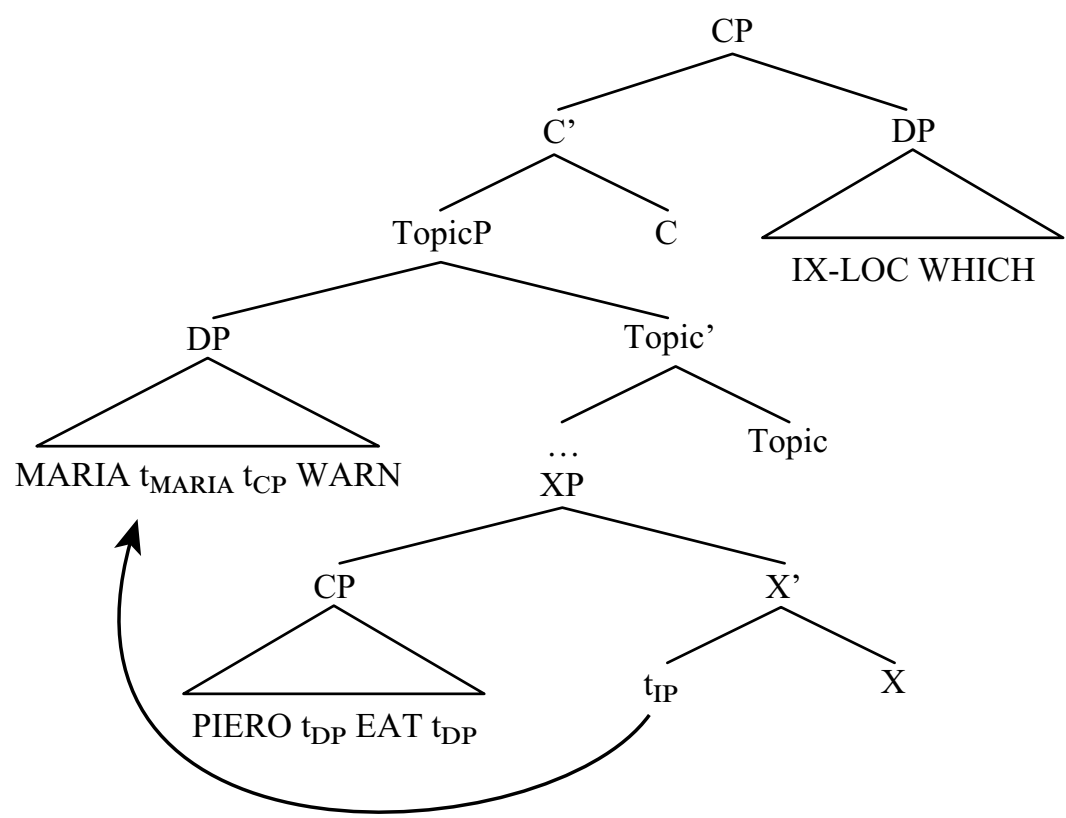

Figure 10. D-linked wh-phrase in clause-final complements: IP topicalization.

Turning back to the islandhood of CPs in topic position, we would like to focus on the contrast between sentential-like and control complements. While wh-extraction is impossible in the former configuration (even in d-linked contexts), extraction of simple non d-linked wh-phrases is possible in the latter, as shown in (48), repeated here as (74).
$\mathrm{br}$
a. BUY GIANNI FORGET WHICH
b. $\left[_{\mathrm{CP} \text { matrix }}\left[_{\text {Topic }}\left[{ }_{\mathrm{CP} \text { subordinate }} \mathrm{t}_{\mathrm{WHICH}} \mathrm{BUY}\right]\left[_{\text {IP }}\right.\right.\right.$ GIANNI FORGET $]$ WHICH $]$ 'What has Gianni forgotten to buy?'

In order to account for the contrast between (71c) and (74), one may assume that the "topic island" can be violated in the case of control complements thanks to their infinitival status (pretty much in the same vain in which simple wh-phrases can move out of center-embedded control complements). Note that this assumption is far from being innocent for three reasons: First, the sentential complement is base-generated in the topic phrase (under the current analysis), and wh-movement from the topic phrase into SpecCP must somehow be stipulated. Second, a paradox seems to emerge since the 
topicalized complement behaves as a strong island for d-linked wh-movement while it does not play any significant role when simple wh-movement out of a control complement is at play. Third, this assumption leaves unexplained why wh-extraction out of clause-final control complements is only allowed in d-linked contexts, as was shown in (50b) above (the verb WANT being a crucial exception).

We will address the first two issues with a more radical proposal in the next section, while we discuss the third one here. The contrast between topicalized and clause-final control complements is even more remarkable considering our claim that clause-final complements are derived from a center-embedded configuration. Specifically, it is surprising that a simple wh-phrase cannot escape the control complement before scrambling (and remnant movement), while a d-linked wh-phrase can. In order to account for this fact, we would like to appeal to processing difficulties in the interpretation of the final output. The problem, we argue, is due to the fact that it is hard to avoid role shift in the case of clause-final control complements. Under role shift, the emerging interpretation is that of an indirect question. Indeed, this is what our informant produced once asked to cope with that specific sign order. Apparently, d-linked wh-questions do not suffer from this difficulty. Interestingly, when the interference of role shift can be removed, simple wh-extraction becomes possible, as in the case of control complements introduced by WANT in (49a).

\subsection{One starting point - many outcomes}

At this point, the picture of sentential complementation in LIS still involves two different strategies (in addition to wh-cleft): either the complement is base-generated in topic position, or it is generated in the center-embedded position. In the latter case, the complement is then either "licensed" by special morphosyntactic strategies or scrambled out of that position. In this section, we attempt to get rid of the base-generated topic strategy and provide a unified derivation according to which all complements are base-generated in the canonical center-embedded position. Then, given the different options offered by the grammar of LIS to cope with processing limitations, the various outcomes are derived. This goal is relatively easy to reach once we look at the analysis we provided for extraction of simple wh-phrases out of control complements. Indeed, once the interference of role shift is removed, the single deep structure in Figure 11 may serve as a starting point for all the three examples in (75). 
(75) a. GIANNI $\left[\mathrm{t}_{\text {WHICH }}\right.$ BUY] FORGET WHICH 'What has Gianni forgot to buy?'

b. $\left[\mathrm{t}_{\mathrm{WHICH}} \frac{\mathrm{br}}{\mathrm{BUY}}\right]$ GIANNI $\mathrm{t}_{\mathrm{CP}}$ FORGET WHICH 'What has Gianni forgot to buy?'

br

c. GIANNI WANT [ $\mathrm{t}_{\text {WHICH }}$ BUY ] WHICH 'What does Gianni want to buy?'

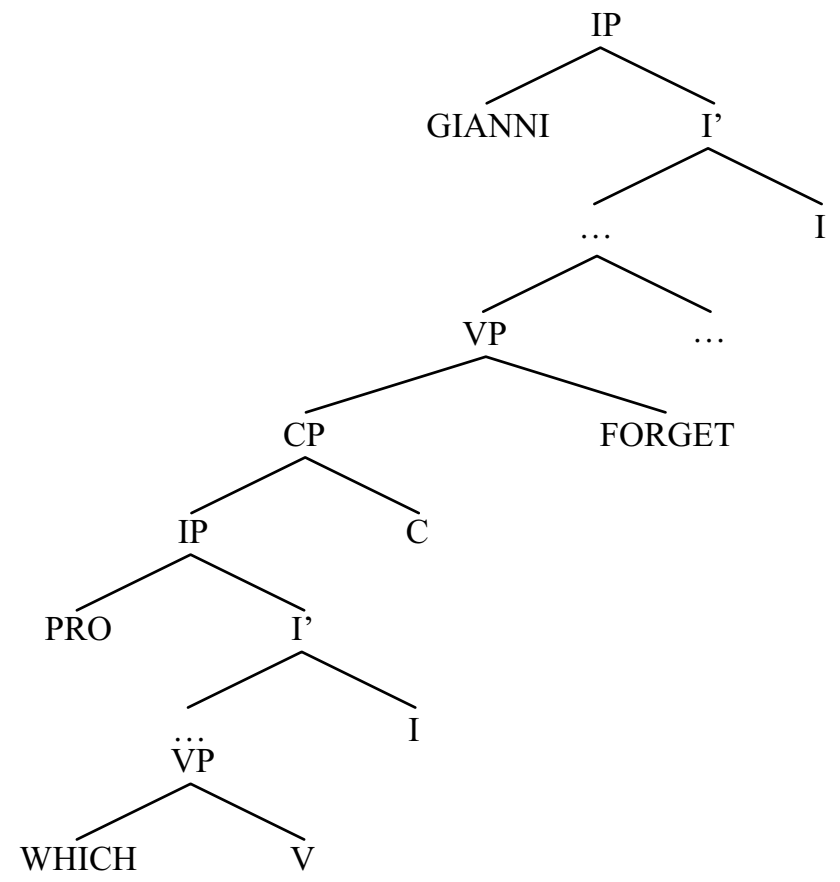

Figure 11. Deep structure of control complements.

From its base position, the wh-phrase cyclically moves to SpecCP deriving (75a). Topicalization of the complement would then derive (75b), while scrambling and remnant movement would derive (75c). Under this view, the paradox of the topic phrase being a strong island for d-linked wh-phrases in sentential-like complements but not for simple wh-movement out of controlled complements is partially removed. Yet, by proposing that topicalized sentential-like complements are not base-generated in the topic phrase, we still have to explain why topicalization cannot co-occur with d-linked 
wh-extraction, that is, why a derivation along the lines proposed for $(75 b)$ is not allowed for (76).

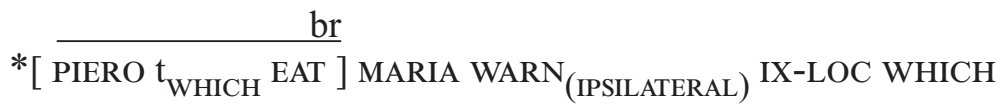

The explanation we offer is again based on the combination of syntactic and processing factors. Specifically, what makes (76) unacceptable is the cumulative effect of the processing costs of escaping the sentential-like complement island and the additional cost of moving a wh-phrase across a [+topic feature.$^{39}$ In other words, the topic feature generates a mild minimality effect in LIS. In contrast, in the example in (75b), there is no island effect because the complement is not sentential-like, and only minimality is violated. In the case of sentential-like complements in clause-final position, there is no minimality violation because no topic feature is present, and the constraint imposed by the sentential-like island is by-passed by the d-linked status of the wh-phrase. ${ }^{40}$

\section{Conclusion}

In this paper, we extended previous works on sentential complementation in LIS by exploring new domains of sentential complementation like those of raising and impersonal constructions. We replicated patterns reported for role shift and center-embedding in LSC, and we uncovered new strategies allowing sentential-like complements to remain in center-embedded position. We showed that all these strategies involve a special use of the signing space. We exploited these options to probe for further levels of centerembedding, which are also possible in LIS once the appropriate morphological mechanisms are at play. The linguistic import of the analysis developed here is similar to the one previously proposed in Geraci, Cecchetto \& Zucchi (2008), although we offered a more comprehensive view of the phenomena and we partially revised their formal proposal. According to them, the fact that sentential-like complements are found in peripheral positions is the answer that LIS grammar provides to a general processing constraint banning center-embedded configurations. However, the further evidence that we provided in this paper shows that there are alternative strategies to deal with the processing costs of center-embedding and that displacement is not the only solution that the grammar of LIS has to offer. 
The investigation of wh-extraction patterns further contributed to a complex picture in which processing factors play a central role in shaping the preferred options, as in the case of wh-movement from the matrix subject position, and in allowing otherwise unacceptable constructions, as in the case of d-linked wh-phrases.

Taken together, these facts allowed us to propose a unified account according to which all sentential complements are base-generated in the center-embedded position, as one would expect given the macroscopic structure of LIS, and the different outcomes are shaped by the specific architecture of the grammar of LIS in combination with general strategies of processing cost reduction.

\section{Acknowledgments}

We would like to thank our LIS informant, Mirko Santoro, for his invaluable input that helped us to understand the subtle nuances among the different options we were testing. The research leading to these results has received funding from the Agence Nationale de la Recherche (grants ANR-10LABX-0087 IEC and ANR-10-IDEX-0001-02 PSL). Part of this work was also funde by the ERC grant FRONTSEM (PI: Philippe Schlenker). Part of the data discussed here have been presented at the $40^{\text {th }}$ IGG Conference in Trento and at the Institut Jean-Nicod LINGUAE Seminar, and we would like to thank the audiences who attended our talks. Special thanks are also due to Emmanuel Chemla, Luigi Rizzi, and Philippe Schlenker for helpful comments.

\section{Notes}

1. Informally, a sentential-like complement is a sentential complement that retains the syntactic relation to its subject and its other arguments as if it were in a matrix clause (Noonan 2007). This syntactic independence is lost in other types of sentential complements like control and raising constructions.

2. Some of these actually replicate data previously obtained from our informant in the study by Geraci, Cecchetto \& Zucchi (2008), since he already participated in that study as informant. Unfortunately, given time and resource limitations, we have not been able to consult other native signers.

3. Laudanna \& Volterra (1991) claim that the unmarked order in LIS is SVO, although other orders are attested as well. Branchini \& Geraci (2011) conducted a preliminary corpus analysis that reveals that several structural and social factors conspire in determining the position of the object. Word 
order variation among signers is well attested in other sign languages as well; however, what is relevant for the following discussion are the options accepted by our informant, and the LIS of our informant is consistently head-final.

4. The derivation of the order (1c) is not trivial and requires at least two steps. Indeed, the process of subject-verb topicalization must be preceded by movement of the object DP out of the to-be-topicalized constituent. This first movement can be attributed to several potential sources: scrambling, object shift, or even focus movement.

5. The fact that agreement can be marked non-manually in LIS has already been informally observed. However, to our knowledge, the assumption that this specific marking corresponds (and is equivalent) to agreement is made for the first time in this paper.

6. Another strategy of marking agreement will be introduced in Section 3. This special alternative strategy mostly emerges in connection with complex syntactic structures and applies to some verbs which are body-anchored in their citation form. It consists in detaching the verb from the body. The verb is then articulated in the spatial location associated with the subject.

7. It is not clear to us whether some form of non-manual marking is also present or required in examples like (5). However, our focus is only on clear cases of body lean because they will be relevant once the issue of center-embedding is addressed.

8. Wh-questions normally come with a specific non-manual marker (roughly furrowed eyebrows) which may spread over specific syntactic domains (Cecchetto, Geraci \& Zucchi 2009). However, since the presence of this nonmanual marker is not crucial for the facts described in this paper, it will be systematically omitted.

9. In order to get the right constituency for the spreading domain, we assume a derivation similar to the one in (1c) in the text.

10. We will see in Section 4 that this limitation is weakened once wh-questions are considered.

11. Throughout the paper, we adopt a traditional view of control. However, nothing in our data excludes movement approaches to control constructions.

12. For reasons not entirely clear to us, this option is not available with all complement-taking predicates.

13. In a nutshell, Geraci (2014) argues that subjects and objects are mapped onto default positions in LIS, when no mental space representation is available (i.e. when the space is used as a token space in the sense of Liddell (2003)). For a detailed presentation of the analysis of the signing space in these and other constructions, see Geraci (2014).

14. The use of time adverbs as an indication that the subject is not in topic position was also used in Cecchetto et al. (2006). However, it is worth noting that both positional and non-manual information are to be taken into account in order to 
establish that the subject GIANNI is not further displaced with respect to the canonical subject position of SEEM. This is so because it is possible to find brow raise ('br') on the subject even if it follows the time adverb, as shown in (i).

br

\section{(i) YESTERDAY GIANNI LOTTERY WIN \\ 'Yesterday Gianni won the lottery.'}

15. Relative clauses would be an ideal test to evaluate the effect of structural heaviness. Unfortunately, LIS does not have the structural equivalent of English relative clauses. Indeed, the relativization process generates either correlative constructions (Cecchetto et al. 2006) or internally headed relative clauses (Branchini \& Donati 2009). Whatever the appropriate fine-grained analysis of these constructions, the important fact is that both involve fronting of the relativized element. One may even speculate that these relativization strategies are a solution to avoid sentential center-embedding.

16. Notice that in this example, role shift allows the signer to take on the role of the embedded subject. In this respect, role shift is probably also introducing a constructed action (Liddell 2003).

17. The sign WARN does not normally show overt spatial agreement with the subject. We consider this use of WARN as a special case of verb detachment like the one discussed in more detail in the context of example (33).

18. Unless relevant for the discussion, indirect object agreement will not be indicated.

19. Note that under role shift, WARN is used in its citation form, as in the example in (31).

20. Interestingly, our informant reports that some signer may allow a detached version of SAY. We expect that those signers will also allow center-embedding in these cases.

21. One non-trivial aspect that is shared by all cases discussed up to this point (role shift, verb detachment, and body lean), is that while the examples reported above do not involve apparent topicalization of the matrix subject (in all cases, the subject is produced with neutral facial expression), the most natural option is to have a topicalized subject. This may indicate a tendency to reorganize the manual material according to main information structure concepts. The result is that although partial linear order is not affected, the entire constructions are now made up of smaller prosodic units, which can be more easily parsed.

22. While some varieties of LIS have two different signs for introducing simple and d-linked wh-questions, our main informant has a strong preference for using only one form to cover both functions. Specifically, he uses the sign WHICH, which is normally associated with d-linked wh-phrases in other varieties of LIS. We stick to the convention of glossing the wh-sign as WHICH, even when its function is not that of a d-linked wh-phrase, as the reader may infer from the translation we propose. 
23. For our informant, role shift is not possible with topicalized complements.

24. We are not considering short movement yielding the indirect question interpretation.

25. We do not know whether null objects are licensed under spatial agreement in LIS; the facts are unclear and more research is needed in this domain (see also the almost minimal pair involving role shift). However, EAT is a plain verb in LIS, therefore it is not supposed to license null objects. This fact could explain why (58c) and (59c) are not acceptable as bi-clausal utterances with a null object in the first clause.

26. Alternatively, one may argue that these are cases of backward control (Polinsky \& Potsdam 2002), namely that the visible nominal element sits in the subject position of the embedded clause and a co-indexed empty slot is left in the matrix clause. Notice, however, that even in this case, the location in the signing space has to be shared by the relevant argument of the matrix and embedded clause.

27. Lillo-Martin (1995) was the first one to propose a syntactic account of quotational and non-quotational uses of role shift in American Sign Language by appealing to a unique Point of view predicate sitting in the head of a dedicated Point of view phrase. Zucchi (2004) excluded this option for LIS on the basis of two facts: (i) quotational and non-quotational uses of role shift cannot be explained by postulating a unique semantics for the point of view operator; (ii) the syntactic evidence for that projection is based on American Sign Language data that have later been questioned in a reply to Lillo-Martin's paper by Lee et al. (1997). Our paper has nothing to add to the first issue raised by Zucchi (2004), and indeed, we acknowledge that the main impact of role shift in sign language is in the semantic component. However, the new LIS data presented in Sections 3 and 4 clearly show a visible effect of role shift in the overt syntax. We have not yet detected specific sign order differences induced by quotational and non-quotational uses of role shift in the syntax of LIS (ideally, one would have expected wh-extraction to be possible only in non-quotational uses of role shift, but unfortunately, this does not seem to be case in LIS). Thus, we adopt a unique syntax to describe role shift in LIS, although the semantics may still remain differentiated, as proposed in Zucchi (2004), or unified, as proposed in Quer (2005) after Schlenker (2003).

28. Whether the matrix verb, after incorporation, further head-moves to the head of the matrix Speech Act Phrase in the overt syntax is hard to determine. One may speculate that this movement is optional and that differences in spreading of the role shift non-manual marker - in particular whether it co-occurs with the matrix verb or not - may signal this optional movement.

29. This is the case if we assume (i) that the relevant topic phrase is hierarchically higher than the Speech Act Phrase, and (ii) that topicalization cannot skip the Speech Act Phrase (possibly for minimality reasons). 
30. Alternatively, a two-step derivation is needed (in addition to the incorporation of the point of view predicate). In the first step, the sentential complement moves to a left-branching specifier of a functional projection. In the second step, remnant movement displaces the matrix subject and verb to a higher projection. Under this analysis, further displacement of the complement to topic position should be blocked by some additional stipulation. Notice that this analysis of clause-final complements under role shift closely resembles the derivation proposed in Geraci, Cecchetto \& Zucchi (2008) for clause-final sentential objects without role shift. One argument against this analysis for role-shifted complements comes from a fact reported in Geraci, Cecchetto \& Zucchi (2008), namely that with complements that are not under role shift, repetition of the matrix subject and verb may frame the sentential complement, as shown in (i). The authors take this option as showing partial spell-out of the lower copy of the constituent undergoing remnant movement. Therefore, (i) and (ii) are derived basically in the same way.

(i) GIANNI SAY PIERO BIKE FELL (IX-3) SAY

(ii) GIANNI SAY PIERO BIKE FELL

'Gianni said that Piero fell off the bike.'

The fact that the same pattern is not possible when the complement is under role shift, as shown in (iii), can be taken as partial evidence against a two-step derivation for examples like (65).

\section{role shift}

\section{(iii) *GIANNI SAY PIERO BIKE FELL SAY}

A second argument against a remnant movement treatment of clause-final complements under role shift comes from the distribution of role shift nonmanual markers. Indeed, syntactic constituency is broken after remnant movement and the prosody-syntax isomorphism is lost. Additional stipulations for the correct prosodic constituency have to be made to capture the correct spreading domain (see also endnote 28).

31. An anonymous reviewer suggested that this fact and the fact that a topicalized sentential-like CP may co-occur with a resumptive pronoun could be taken as evidence that sentential-like complements are always generated in an adjunct position with an overt or a null resumptive pronoun in object position, thus deriving their islandhood status. Although interesting, this alternative explanation would leave the following questions unexplained:

(i) What is the position of center-embedded sentential complements?

(ii) Why are overt resumptive pronouns impossible when the complement is clause-final or center-embedded?

(iii) Why are overt resumptive pronouns impossible with topicalized control constructions? 
(iv) Why is extraction under d-linking only prohibited in the topicalized configuration?

Point (iii) is crucial because it is likely that the same syntactic position (marked by topic non-manual marking) and possibly the same derivation as with sentential-like complements is involved.

Alternatively, one may tentatively argue that LIS has no sentential-like complements altogether, and that these constructions involve some sort of nominalization. There are at least two problems with this type of analysis: First, there is no overt prosodic or morphological evidence of any nominalization process. Second, the contrast between the canonical SOV order found with NP complements and the special requirements of "nominalized sentences" cannot be accounted for without additional stipulations. In other words, why would nominalized sentences require special morphological marking on the matrix verb?

Finally, one might argue that sentential-like complements are actually internally headed relative clauses like in Adyghe (Caponigro \& Polinsky 2011). While this move would nicely explain the islandhood status of these constructions, such an analysis would run into other problems. Specifically, the syntax of internally headed clauses (or correlatives) in LIS is quite restricted in that the relative clause must be fronted (Cecchetto et al. 2006; Branchini \& Donati 2009). Hence, all the cases in which the sentential-like complement occurs in clause-final position could not be accommodated without further ad hoc stipulations.

32. The special status of d-linked wh-questions is also observed in spoken languages. Frazier \& Clifton (2002) report examples in which superiority is suspended in d-linked wh-questions. The relevant contrast is given in (i) and (ii). Superiority cannot be violated in simple wh-questions (i), while it is violated in d-linked questions (ii).

(i) a. Mary asked [who [ $\mathrm{t}_{\text {who }}$ read what $]$ ?

b. *Mary asked [what [who read $\left.\mathrm{t}_{\text {what }}\right]$ ]?

(ii) a. Mary asked which man $\left[\mathrm{t}_{\text {which man }}\right.$ read which book]?

b. Mary asked which book [which man read $\left.t_{\text {which book }}\right]$ ?

Moreover, Falco (2007) convincingly shows that d-linked wh-questions are not sensitive to weak crossover effects.

33. That d-linked wh-questions have a special status in LIS was already found in Cecchetto et al. (2009), who report that d-linking is the only environment allowing wh-phrases to remain in situ, as already shown in (9) above.

34. Geraci, Cecchetto \& Zucchi (2008) were speculating that the unacceptability of (70) could be attributed to the same type of island violation. The contrast between (71b) and (71c) proves that this is not the case. 
35. In Section 5.3, we will offer an alternative derivation, where base-generation of the topicalized constituent is no longer necessary.

36. We cannot be more precise on the specific syntactic position of the scrambled complement because we do not yet have clear evidence for a fine-grained structure of the IP and the CP domain in LIS. For this reason, the target projection is indicated with a generic XP label in the representation in Figures 8-10. At present, we cannot establish whether this position counts as an A or an A'-position, although the fact that it is higher than the subject may lead us to speculate it is an A'-position. We leave these issues for future research. An anonymous reviewer pointed out that if this type of scrambling were similar to that found in spoken languages, then the affected constituent should be specific or referential. Unfortunately, we do not have independent evidence for this from our LIS data. However, evidence that specificity could be somehow involved in this operation can be traced in the fact that the scrambled constituent contains (the trace of) a d-linked wh-phrase (for the fact that d-linked whphrases are [+specific], see Falco (2007)).

37. In purely derivational approaches to syntax, these derivations require an intermediate landing site for the wh-phrase before the complement is scrambled. Following Chomsky (2001), one may take this intermediate landing site to be the matrix vP phase.

38. Under a phase theory approach, topic movement and wh-movement happen simultaneously when the matrix CP layers are introduced.

39. One may even attempt to relate this constraint to the incompatibility between the prototypical topic marker (raised eyebrows) and the prototypical whmarker (furrowed eyebrows), or by adopting for LIS a claim made in Wilbur \& Patschke (1999) for American Sign Language, namely that brow raise marks non-wh A'-positions.

40. Notice that we cannot appeal to a cumulative effect between the sententiallike islandhood and linear distance between the gap (in the fronted topic position) and the filler (in the matrix SpecCP) here because the linear distance is identical in the acceptable example in (73). Crucially, no topicalization is involved in this case. 


\section{References}

Ackema, Peter \& Ad Neeleman. 2002. Effects of short-term storage in processing rightward movement. In Sieb Nooteboom, Fred Weerman \& Frank Wijnen (eds.), Storage and computation in the language faculty, 219-256. Dordrecht: Kluwer Academic Publishers.

Arnon, Inbal, Neal Snider, Philip Hofmeister, T. Florian Jaeger \& Ivan A. Sag. 2007. Cross-linguistic variation in a processing account: The case of multiple whquestions. In Proceedings of BLS 32.

Babyonyshev, Maria \& Edward Gibson. 1999. The complexity of nested structures in Japanese. Language 75(3). 423-450.

Branchini, Chiara, Anna Cardinaletti, Carlo Cecchetto, Caterina Donati \& Carlo Geraci. 2013. Wh-duplication in Italian Sign Language (LIS). Sign Language \& Linguistics 16(2). 157-188.

Branchini, Chiara \& Caterina Donati. 2009. Relatively different: Italian Sign Language relative clauses in a typological perspective. In Anikó Lipták (ed.), Correlatives cross-linguistically, 158-191. Amsterdam: John Benjamins.

Branchini, Chiara \& Carlo Geraci. 2011. L'ordine dei costituenti in LIS: risultati preliminari. In Anna Cardinaletti, Carlo Cecchetto \& Caterina Donati (eds.), Grammatica, lessico e dimensioni di variazione nella LIS, 113-126. Milano: Franco Angeli.

Caponigro, Ivano \& Maria Polinsky. 2011. Relative embeddings: a Circassian puzzle for the syntax/semantics interface. Natural Language \& Linguistic Theory 29(1). 71-122.

Cecchetto, Carlo. 2012. Sentence types. In Roland Pfau, Markus Steinbach \& Bencie Woll (eds.), Sign language. An international handbook, 292-315. Berlin: De Gruyter Mouton.

Cecchetto, Carlo, Carlo Geraci \& Sandro Zucchi. 2006. Strategies of relativization in Italian Sign Language. Natural Language \& Linguistic Theory 24(4). 945975.

Cecchetto, Carlo, Carlo Geraci \& Sandro Zucchi. 2009. Another way to mark syntactic dependencies. The case for right-peripheral specifiers in sign languages. Language 85(2). 278-320.

Chomsky, Noam. 2001. Derivation by phase. In Michael Kenstowicz (ed.), Ken Hale: A life in language, 1-52. Cambridge, MA: MIT Press.

Chomsky, Noam \& George A. Miller. 1963. Introduction to the formal analysis of natural languages. In R. Duncan Luce, Robert R. Bush \& Eugene Galanter (eds.), Handbook of mathematical psychology, Volume 2, 269-321. New York: John Wiley. 
Crasborn, Onno \& Han Sloetjes. 2010. Using ELAN for annotating sign language corpora in a team setting. In: Proceedings of the $4^{\text {th }}$ Workshop on the Representation and Processing of Sign Languages: Corpora and Sign Language Technologies, LREC 2010.

De Cuba, Carlos Francisco. 2007. On (non)factivity, clausal complementation and the CP-field. PhD dissertation, Stony Brook University, New York.

Falco, Michelangelo. 2007. Weak crossover specificity and LF chains. In Luis Eguren \& Olga Fernández Soriano (eds.), Coreference, modality, and focus, 19-44. Amsterdam: John Benjamins.

Frazier, Lyn \& Charles Clifton. 2002. Processing "d-Linked" Phrases. Journal of Psycholinguistic Research 31(6). 633-659.

Geraci, Carlo. 2006. Negation in LIS (Italian Sign Language). In Leah Bateman \& Cherlon Ussery (eds.), Proceedings of NELS 35, 217-229. Amherst, MA: GLSA.

Geraci, Carlo. 2009. Phase theory, linearization, and zig-zag movement. In Kleanthes K. Grohmann (ed.), Explorations of phase theory: Interpretation at the interfaces, 133-159. Berlin: Mouton de Gruyter.

Geraci, Carlo \& Carlo Cecchetto. 2013. Neglected cases of rightward movement. When wh-phrases and negative quantifiers go to right. In Gert Webelhuth, Werner Abraham, Manfred Sailer \& Heike Walker (eds.), Rightward Movement in a Comparative Perspective, 212-241. Amsterdam: John Benjamins Publishing Company.

Geraci, Carlo. 2014. Spatial syntax in your hands. In Jyoti Iyer \& Leland Kusmer (eds.), NELS 44: Proceedings of the Forty-Fourth Annual Meeting of the North East Linguistic Society Vol 1, 123-134, GLSA, Amherst.

Geraci, Carlo, Robert Bayley, Anna Cardinaletti, Carlo Cecchetto \& Caterina Donati. 2015. Variation in Italian Sign Language (LIS): The case of wh-signs. Linguistics 53(1). 125-151.

Geraci, Carlo, Carlo Cecchetto \& Costanza Papagno. 2010. Remembering phonologically in a language without sounds. In Robert V. Nata (ed.), Progress in education, Volume 20, 141-151. Hauppauge: Nova Science Publishers.

Geraci, Carlo, Carlo Cecchetto \& Sandro Zucchi. 2008. Sentential complementation in Italian Sign Language. In Michael Grosvald \& Dionne Soares (eds.), Proceedings of the $38^{\text {th }}$ Western Conference on Linguistics, 46-58. Davis: Department of Linguistics University of California.

Geraci, Carlo \& Josep Quer. 2014. Determining argument structure in sign languages. In Asaf Bachrach, Isabelle Roy \& Linnaea Stockall (eds.), Structuring the argument, 45-60. Amsterdam: John Benjamins.

Gibson, Edward. 1998. Linguistic complexity: locality of syntactic dependencies. Cognition 68. 1-76. 
Homer, Vincent \& Carlo Geraci. 2013. Can’t we make it possible? Maybe (not). Poster presented at Theoretical Issues in Sign Language Research (TISLR 11), London, July 2013.

Kayne, Richard S. 1994. The antisymmetry of syntax. Cambridge, MA: MIT Press.

Laudanna, Alessandro \& Virginia Volterra. 1991. Order of words, signs, and gestures: A first comparison. Applied Psycholinguistics 12. 135-150.

Lee, Robert G., Carol Neidle, Dawn MacLaughlin, Benjamin Bahan \& Judy Kegl. 1997. Role shift in ASL: A syntactic look at direct speech. In Carol Neidle, Dawn MacLaughlin \& Robert G. Lee (eds.), Syntactic structure and discourse function: An examination of two constructions in American Sign Language, 24-45. Report \#4, ASLLRP, Boston University.

Liddell, Scott K. 2003. Grammar, Gesture and Meaning in American Sign Language. Cambridge, UK: Cambridge Univerisity Press.

Lillo-Martin, Diane. 1995. The point of view predicate in American Sign Language. In Karen Emmorey \& Judy S. Reilly (eds.), Language, gesture, and space, 155-170. Hillsdale, NJ: Lawrence Erlbaum.

Miller, George A. \& Noam Chomsky. 1963. Finitary models of language users. In R. Duncan Luce, Robert R. Bush \& Eugene Galanter (eds.), Handbook of mathematical psychology, Volume 2, 419-491. New York: John Wiley.

Meir, Irit, Carol A. Padden, Mark Aronoff \& Wendy Sandler. 2007. Body as subject. Journal of Linguistics 43. 531-563.

Noonan, Michael. 2007. Complementation. In Timothy Shopen (ed.), Language Typology, 52-150. Cambridge, UK: Cambridge Univerisity Press.

Padden, Carol. 1988. Interaction of morphology and syntax in American Sign Language. New York: Garland Press.

Polinsky, Maria \& Eric Potsdam. 2002. Backward control. Linguistic Inquiry 33(2). 245-282.

Quer, Josep. 2005. Context shift and indexical variables in sign languages. In Effi Georgala \& Jonathan Howell (eds.), Proceedings from Semantics and Linguistic Theory 15, 152-168. Ithaca, NY: CLC Publications.

Quer, Josep. 2012. A modality-free account of the position of clausal arguments. Paper presented at Formal and Experimental Advances in Sign Language Theory (FEAST), Warsaw, June 2012.

Rizzi, Luigi. 2006. On the Form of Chains: Criterial Positions and ECP Effects. In Lisa Cheng \& Norbert Corver (Eds.) On Wh Movement. Cambridge, MA: MIT Press.

Ross, John Robert. 1967. Constraints on variables in syntax. Cambridge, MA: PhD dissertation, MIT.

Schlenker, Philippe. 2003. A plea for monsters. Linguistics \& Philosophy 26. 29120. 
Speas, Margaret. 2000. Person and point of view in Navajo direct discourse complements. In Eloise Jelinek (ed.), WCCFL papers in honor of Ken Hale. Cambridge, MA: MIT Press.

Speas, Margaret. 2004. Evidentiality, logophoricity, and the syntactic representation of pragmatic features. Lingua 114. 255-276.

Volterra, Virginia (ed.). 1987. La lingua italiana dei segni: la comunicazione visivogestuale dei sordi. Bologna: Il Mulino.

Wilbur, Ronnie B. \& Cynthia G. Patschke. 1999. Syntactic correlates of brow raise in ASL. Sign language \& Linguistics 2(1). 3-41.

Zucchi, Sandro. 2004. Monsters in the visual mode?. Manuscript, Università degli Studi di Milano. 